\title{
ANÁLISE DO DESENVOLVIMENTO DO RITMO DO INGLÊS-L2 POR BRASILEIROS POR MEIO DE TRÊS MÉTRICAS RÍTMICAS ${ }^{1}$
}

\author{
An Analysis of the Development of the Rhythm of English-L2 by Brazilian \\ Learners through Three Rhythmic Metrics
}

\author{
Leonardo Antonio Silva TEIXEIRA \\ Programa de Pós-Graduação em Linguística \\ Universidade Federal do Ceará \\ leoteixeira.professor@gmail.com \\ https://orcid.org/0000-0002-4905-4259 \\ Ronaldo Mangueira LIMA JR. \\ Universidade Federal do Ceará \\ ronaldojr@letras.ufc.br \\ https://orcid.org/0000-0002-8610-0306
}

RESUMO: O objetivo deste estudo é descrever e discutir o desenvolvimento do ritmo do inglês-L2 por aprendizes brasileiros por meio de três métricas rítmicas propostas para a classificação rítmica de línguas: $\Delta \mathrm{C}-\mathrm{\%} \mathrm{V}$; Varcos; e PVIs. Foram analisados quatro corpora de produção oral. Cinco aprendizes brasileiros de inglês-L2 foram gravados lendo um texto em inglês no início do curso de Letras-Inglês, e mais uma vez quatro semestres depois, após terem cursado duas disciplinas de fonologia da língua inglesa. Eles também foram gravados lendo uma versão desse texto traduzida para o português. Além dos aprendizes, cinco falantes nativos de inglês norte-americano foram gravados lendo o mesmo texto em inglês. Sendo assim, o estudo também busca avaliar possíveis efeitos da instrução explícita de pronúncia sobre o desenvolvimento do ritmo do inglês-L2 dos aprendizes. Os resultados das três métricas posicionaram o português-L1 e o inglês-L1 em espaços rítmicos distintos, conforme previsto pela literatura; e posicionaram o inglês-L2 da primeira gravação distante tanto do inglês-L1 como do português-L1, e o inglês-L2 da gravação posterior próximo ao inglês-L1, sugerindo um percurso de desenvolvimento em direção à língua alvo, porém sem necessariamente partir dos padrões rítmicos da L1. Os resultados também indicam efeitos positivos do ensino explícito de pronúncia.

\footnotetext{
${ }^{1}$ Este trabalho faz parte de um projeto parcialmente financiado pelo CNPq, processo 438823/2018-4.
}

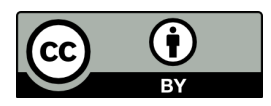


PALAVRAS-CHAVE: aquisição fonológica; prosódia; métricas rítmicas; instrução explícita; inglês L2.

\begin{abstract}
This study aims to describe and discuss the development of the rhythm of English-L2 by Brazilian learners by means of three rhythmic metrics proposed for the rhythmic classification of languages: $\Delta \mathrm{C}-\% \mathrm{~V}$; Varcos; and PVIs. Four corpora of oral production were analyzed. Five Brazilian learners of English-L2 were recorded reading a text in English at the beginning of their college studies in English Language Teaching, and again four semesters later, after having taken two English phonology courses. They were also recorded reading a version of the text translated into Portuguese. Besides the learners, five native speakers of North American English were recorded reading the same text in English. Thus, this study also seeks to evaluate possible effects of explicit pronunciation instruction on the development of the rhythm of English by the learners. The results for the three metrics placed Brazilian Portuguese and English-L1 in different rhythmic spaces, as predicted by the literature; and positioned the English-L2 of the first recording far from both English-L1 and Brazilian Portuguese, and the English-L2 of the later recording closer to English-L1, suggesting a developmental route towards the target language, but not necessarily starting from the rhythmic patterns of the L1. The results also suggest positive effects of the explicit teaching of pronunciation. KEY-WORDS: phonological acquisition; prosody; rhythmic metrics; explicit instruction; L2 English.
\end{abstract}

\title{
INTRODUÇÃO
}

No âmbito dos estudos em aquisição de línguas não nativas (L2 ${ }^{2}$ ), parece haver maior ênfase em pesquisas que envolvem aspectos segmentais em comparação a aspectos prosódicos (THOMSON; DERWING, 2015; LI; POST, 2014). A menor ênfase em aspectos prosódicos também se reflete em modelos de aquisição de L2, tais como o Modelo de Aquisição da Fala - Speech Learning Model (FLEGE, 1995) e sua versão revisada - Revised Speech Learning Model (FLEGE; BOHN, 2021), bem como o Modelo de Assimilação Perceptual - Perceptual Assimilation Model (BEST, 1995) e sua versão para L2 - Perceptual Assimilation Model of Second Language Speech Learning (BEST; TYLER, 2007), que, ao enfatizarem aspectos segmentais, oferecem poucos subsídios à compreensão do desenvolvimento da prosódia por aprendizes de L2. Esse universo de pesquisa pouco explorado contrasta com evidências que demonstram a

\footnotetext{
${ }^{2}$ Neste trabalho não faremos distinção entre segunda língua e língua estrangeira. 
persistência de padrões prosódicos atípicos da L2 mesmo em usuários de nível avançado (LI; POST, 2014).

Dentre os aspectos prosódicos passíveis de investigação, o ritmo é ainda o menos explorado (WHITWORTH, 2002; GUT, 2012; CUMMING, 2010). Há evidências de que o ritmo pode influenciar o processo de comunicação de maneira global, afetando níveis de grau de acento, inteligibilidade (SILVA JR.; BARBOSA, 2019b) e compreensibilidade (MUNRO; DERWING, 2001; ORDIN; POLYANSKAYA, 2015). Outrossim, o ritmo pode oferecer aos aprendizes pistas acústicas que os guiam na segmentação da cadeia da fala em constituintes prosódicos que realizam múltiplas funções nos campos linguístico, paralinguístico e expressivo (BARBOSA, 2012). Desta forma, o ritmo figura como importante construto a ser explorado em pesquisas sobre aquisição de L2.

A escassez de estudos sobre a aquisição do ritmo de L2 pode estar relacionada à dificuldade de estabelecer a realidade física desse construto. Há pelo menos três ondas nos estudos acerca do ritmo. A primeira geração de estudos remonta ao caráter impressionístico associado ao ritmo, presente na clássica metáfora de Lloyd James (1940), citada por Abercrombie (1967), que se utiliza da dicotomia código Morse versus metralhadora para ilustrar a diferença entre a percepção de ritmos distintos para o inglês e o espanhol, respectivamente. A analogia busca captar a impressão causada pelo tipo de recorrência periódica dos elementos que marcariam o ritmo dessas línguas. Tanto o código Morse como o inglês teriam uma ênfase/alongamento em alguns segmentos intervalados por outros mais curtos, como o código Morse. Já o espanhol teria uma sequência de segmentos com pulsação mais regular, como o som de metralhadora.

Mais tarde, Abercrombie (1967) propôs o conceito de isocronia a fim de formalizar essa diferença perceptual, inaugurando a Hipótese da Isocronia, que buscou fazer uma classificação tipológica entre as línguas do mundo. De acordo com essa proposta, as unidades rítmicas seriam unidades isócronas, ou seja, de mesma duração. Assim, a diferença rítmica entre as línguas poderia ser explicada por qual unidade detém regularidade duracional. Línguas como o inglês seriam classificadas como línguas de ritmo acentual, por terem intervalos interacentuais (entre o início de uma sílaba tônica e o início da próxima) isócronos; e línguas como o espanhol teriam um ritmo silábico, pois suas unidades isócronas seriam as sílabas. Posteriomente, Ladefoged (1975) acrescentou a tipologia de ritmo moraico, para dar conta de línguas como o japonês, que teria a mora como unidade isócrona (LADEFOGED, 1975; LADEFOGED; JOHNSON, 2014).

Sendo assim, a tipologia rítmica, cuja nomenclatura perdura até hoje, foi concebida categoricamente, ou seja, cada língua natural deveria figurar em uma ou 
outra tipologia rítmica. Entretanto, o paradigma isocrônico mostrou-se empiricamente insustentável: quando se considera, por exemplo, que o desvio-padrão de medidas de duração de sílabas e pés silábicos em línguas consideradas de ritmo silábico e acentual, que mede a variabilidade das durações das unidades supostamente isócronas, não é capaz de satisfatoriamente separar tais línguas em categorias distintas (DAUER, 1983). Diversos estudos conduzidos nos anos 70, 80 e 90 demonstraram a implausibilidade da Hipótese da Isocronia, uma vez que intervalos de mesma duração não são encontrados no sinal acústico (CUMMING, 2010), o que suscitou propostas alternativas para explicar a variabilidade do ritmo nas línguas do mundo. Entre elas, surgiu o Modelo Unidimensional de Ritmo (DAUER, 1987), em que o ritmo é concebido como um efeito global em função da estrutura fonológica das línguas naturais, e as categorias mais acentual e menos acentual ocupam, cada uma, um extremo de um continuum rítmico.

A partir de meados dos anos 90, uma segunda onda de estudos em ritmo linguístico emerge seguindo o paradigma de variabilidade e gradiência, e não mais um categórico e isocrônico. Nesse paradigma, a classificação rítmica é buscada em função das características duracionais dos intervalos de referência (vocálicos, consonantais, silábicos etc.), que podem ser computados por meio de índices estatísticos denominados métricas rítmicas. A utilização de métricas rítmicas de maneira bidimensional inicia-se com o estudo seminal de Ramus, Nespor e Mehler (1999), que toma por base uma série de experimentos psicolinguísticos que fornecem evidências de que os bebês percebem a fala como uma sucessão de vogais que variam em termos de duração e intensidade, e que se alternam com períodos de ruídos não analisados.

Com base nessa constatação, a segmentação da fala em consoantes e vogais poderia, segundo Ramus, Nespor e Mehler (1999), dar conta da tipologia rítmica, oferecer subsídios à compreensão da percepção de língua observada nos bebês, e elucidar como o ritmo pode ser extraído do sinal da fala. Na proposta de Ramus, Nespor e Mehler (1999), o desvio-padrão da duração de intervalos consonantais $(\Delta C)$ e a proporção da duração total do enunciado composto de intervalos vocálicos $(\% \mathrm{~V})$ são capazes de diferenciar línguas de ritmo silábico, acentual e moraico, visível se plotadas em um gráfico com $\Delta \mathrm{C}$ e \%V em cada eixo. Ramus, Nespor e Mehler (1999) investigaram, em sua proposta, dados do inglês, polonês e holandês, como representantes da classe de ritmo acentual; francês, espanhol, italiano e catalão, representando línguas de ritmo silábico; e japonês, como tendo ritmo moraico. Como pode ser visto na figura 1 , reproduzida da publicação 
original, as métricas propostas foram capazes de agrupar as línguas de cada tipo rítmico dentro de um espaço gradiente ${ }^{3}$.

Figura 1: Distribuição do inglês (EN), holandês (DU), polonês (PO), espanhol (SP), italiano (IT), francês (FR), catalão (CA) e japonês (JA) em um plano cartesiano com $\Delta \mathrm{C}$ e $\% \mathrm{~V}$ nos eixos, em que as barras representam o erro-padrão.

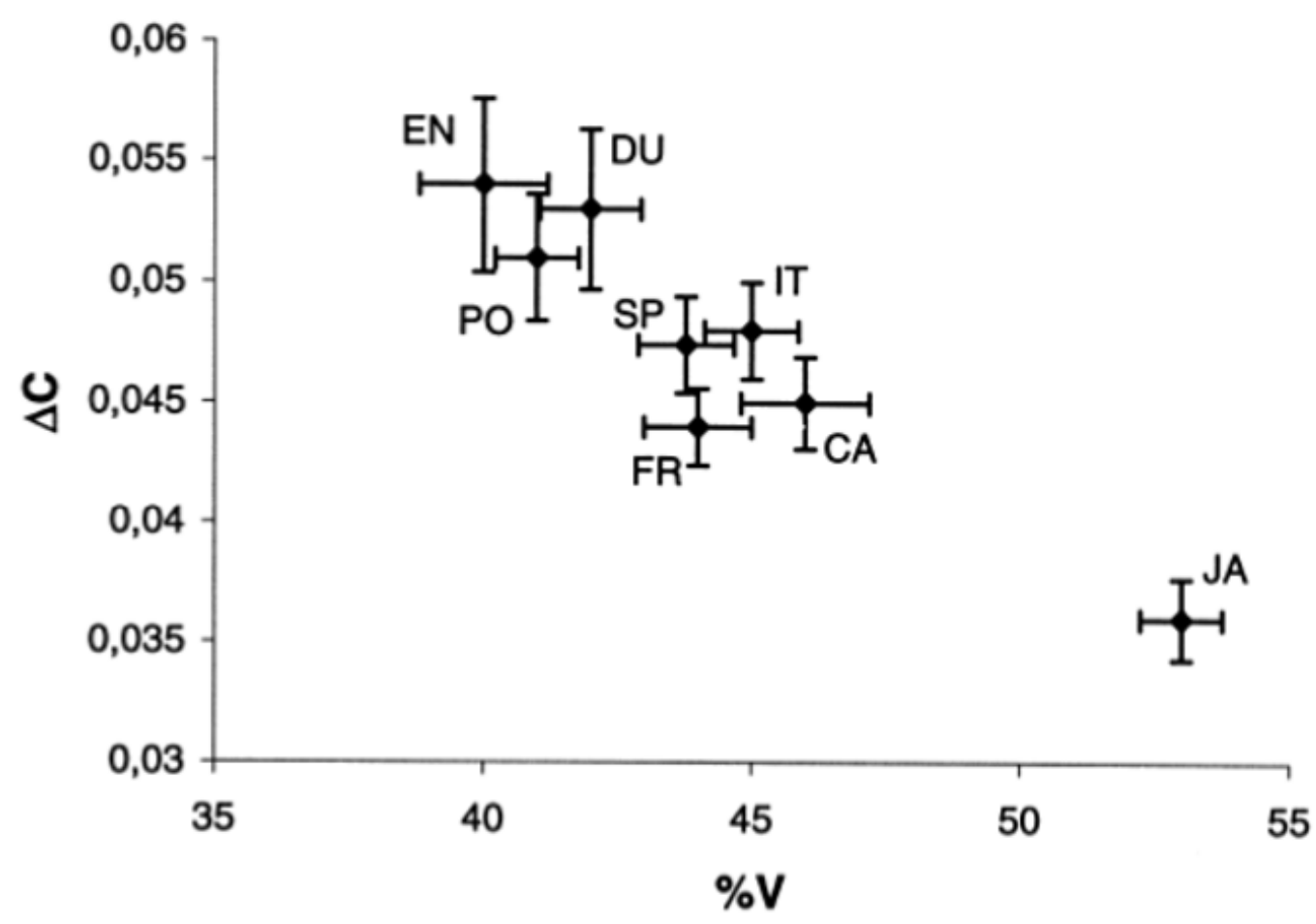

Fonte: Ramus, Nespor e Mehler (1999, p. 273).

No entanto, esses índices mostram-se sensíveis à taxa de elocução, pois, em enunciados com taxa de elocução mais elevada, os intervalos consonantais tendem a ser mais curtos, afetando diretamente o escopo de variação das durações. Como meio de atenuar os efeitos da taxa de elocução, Dellwo (2006) sugeriu que o desvio-padrão da duração dos intervalos consonantais $\Delta \mathrm{C}$ fosse normalizado, dividindo-o pela duração média dos intervalos consonantais. Essa métrica foi chamada de VarcoC (variation coeficient of consonants), por se tratar do coeficiente de variação da duração dos intervalos consonantais:

\footnotetext{
${ }^{3}$ A diferença entre os três ritmos foi significativa em uma ANOVA e também nos pós-testes pareados de Tukey.
} 


$$
\operatorname{Varco} C=\frac{\Delta C}{\text { média }(C)},
$$

O mesmo procedimento passou a ser aplicado também a vogais - VarcoV (WHITE; MATTYS, 2007), a intervalos vocálicos e consonantais sucessivos - VarcoVC (LISS et al., 2009), a sílabas - VarcoS (RATHCKE; SMITH, 2011), e a intervalos vozeados e desvozeados - VarcoUV (DELLWO; FOURCIN; ABBERTON, 2007) a fim de buscar as melhores métricas para a classificação rítmica das línguas.

O que as métricas com base no cálculo de desvio-padrão possuem em comum é o fato de serem consideradas globais, pois buscam explicitar como todos os intervalos de referência do enunciado diferem entre si. Por isso, Low, Grabe e Nolan (2000) argumentam que o cálculo do desvio-padrão da duração de intervalos de referência pode não ser suficiente para distinguir o ritmo de duas línguas ou variedades de uma mesma língua. Esses autores sugerem uma métrica local como meio de captar as diferenças entre intervalos de referência adjacentes, denominada PVI - pairwise variability index, ou, índice de variabilidade pareada, que consiste na média das diferenças entre intervalos de referência sucessivos. Low, Grabe e Nolan (2000) propõem o nPVI-V, cujo ' $\mathrm{V}$ ' indica se tratar da métrica local de intervalos vocálicos, e cujo ' $n$ ' indica a normalização para atenuar os efeitos da taxa de elocução, novamente realizada pela divisão da métrica pela média de duração dos mesmos intervalos. Todo o cálculo pode ser multiplicado por 100 para ficar na escala de 0 a 100, comumente utilizada nas comparações de métricas:

(2)

$$
n P V I(V)=100 \times \frac{\sum_{k=1}^{m-1}\left|\frac{d_{k}-d_{k+1}}{\left(d_{k}+d_{k+1) / 2}\right.}\right| m-1}{(5)}
$$

onde $m$ é o número de intervalos vocálicos e $d_{k}$ é a duração do enésimo intervalo vocálico 
Em teoria, valores menores de nPVI-V são esperados para línguas de ritmo silábico, refletindo menor variabilidade entre os intervalos vocálicos consecutivos; e valores maiores são esperados para línguas de ritmo acentual, em decorrência de uma maior variabilidade resultante da alternância entre vogais longas e breves ou reduzidas. Essa hipótese foi testada e corroborada pelos autores em um estudo comparativo entre o inglês britânico e o inglês singapuriano, em que o nPVI-V mostrou-se capaz de explicar as diferenças rítmicas entre essas línguas. Outra métrica local, rPVI-C, também proposta por esses autores, computa a correlação entre padrões rítmicos e variabilidade na duração de intervalos consonantais em diferentes línguas. Ao contrário de nPVI-C, a normalização não é aplicada a essa métrica ${ }^{4}$, tendo em vista que a taxa de elocução não parece afetar esse coeficiente (LOW; GRABE; NOLAN, 2000).

Grabe e Low (2002) examinaram o nPVI-V e o rPVI-C de 18 línguas, incluindo línguas consideradas prototipicamente silábicas, acentuais ou moraicas, e línguas não investigadas até então. As línguas distribuíram-se em zonas diferentes em um plano gradiente de possíveis categorias rítmicas. No entanto, conforme pontua Fuchs (2016), menos da metade das comparações das diferenças entre as línguas atingiu significância, o que poderia ser atribuído à quantidade de participantes, apenas um por língua. Fuchs (2016) ainda avalia que métricas locais e globais devem ser utilizadas complementarmente, pois "se unidades longas e curtas alternam, isso será bem capturado por métricas locais. Por outro lado, se unidades curtas e longas se agrupam em diferentes partes do enunciado, isso será refletido nas métricas globais"5 (FUCHS, 2016, p. 41).

Cálculos de desvio-padrão e proporção $(\Delta \mathrm{C}$ e $\% \mathrm{~V})$, Varcos, PVIs e outras métricas propostas posteriormente ${ }^{6}$ (FUCHS, 2016) conseguem prever a gradiência rítmica das línguas. Não há consenso, porém, em relação a quais métricas sustentam a percepção de diferentes categorias rítmicas, até porque diferentes estudos às vezes geram resultados conflitantes em métricas distintas (GUT, 2012). Há pouco progresso também em relação à correlação entre os fatores que parecem comprovar a realidade física do ritmo e sua dimensão psicológica. Além disso, as medidas de ritmo parecem variar consoante aos estímulos, às idiossincrasias do falante, aos examinadores, aos métodos de segmentação da cadeia da fala, e aos textos analisados (FUCHS, 2016). Tamanha complexidade, inconsistência de resultados e dificuldade de obtenção de dados robustos

\footnotetext{
${ }^{4}$ Por isso o ' $\mathrm{r}$ ' de "raw" (valor bruto).

${ }^{5}$ if long and short units alternate, this will be captured well by local metrics. On the other hand, if short and long units cluster at different places in the utterance, this will be reflected by global metrics.

${ }^{6}$ Tais como RR, VI, YARD, \%n, \%1, \%Sonorant, etc.

Revista X, v. 16, n. 5, p. 1258-1292, 2021. 
têm suscitado inclusive questionamentos sobre a natureza do ritmo enquanto construto teórico (ARVANITI, 2012).

Esses questionamentos à abordagem da investigação e classificação do ritmo com base em aspectos exclusivamente duracionais têm conduzido a uma terceira onda de estudos acerca do ritmo, que emprega outros correlatos de proeminência, tais quais frequência fundamental $\left(f_{0}\right)$ e intensidade, já que a duração não é o único correlato de proeminência. Nessa perspectiva multidimensional, o ritmo figura como função da distribuição de elementos de proeminência no sinal acústico, que envolve várias dimensões acústicas e pode sofrer influência da língua nativa do falante (CUMMING, 2010; FUCHS, 2016; LOUKINA et. al., 2011; SILVA JR.; BARBOSA, 2019b). Assim, assume-se que a alternância de unidades mais e menos proeminentes em uma língua só pode ser totalmente capturada se diferentes correlatos e dimensões de proeminência forem considerados. É essa perspectiva não categórica, gradiente e multidimensional que orienta a investigação mais ampla do projeto guarda-chuva que abriga este relato preliminar, cujos objetivos gerais serão explicitados ao final desta seção.

No âmbito da aquisição de L2, os estudos acerca do ritmo giram em torno de três questões fundamentais: a) O ritmo de L2 pode ser adquirido?; b) Qual é o percurso de aquisição do ritmo em L2?; c) Qual é a influência do ritmo da L1 sobre o ritmo da L2? Adams (1979) realizou um estudo abrangente acerca da aquisição do ritmo do inglês por aprendizes com diferentes L1s. A autora atribuiu o grau de acento detectado no ritmo da produção desses aprendizes a fatores como: contraste duracional insuficiente entre sílabas acentuadas e não acentuadas; ausência de mecanismos fonológicos de juntura, isto é, transição entre os sons, em que um som é introduzido (ou apagado) no final de uma palavra dependendo da palavra seguinte; pausas inadequadas; e posicionamento incorreto de acento. Esses fatores poderiam indicar transferência de padrões rítmicos da L1 para a L2. Vale ressaltar que Adams utilizou-se de uma abordagem multidimensional de ritmo, por meio da investigação de diferentes correlatos de proeminência $-f_{0}$, duração e intensidade, antecipando uma tendência mais contemporânea de pesquisas sobre o ritmo.

Outros estudos debruçaram-se sobre a aquisição do ritmo em L2 por meio das métricas rítmicas previamente discutidas, variando em função do grau de similaridade e dissimilaridade entre L1 e L2, das medidas utilizadas, e dos procedimentos de coleta e análise de dados. Lin e Wang (2005), por exemplo, realizaram uma investigação acerca dos padrões rítmicos manifestados na interlíngua de aprendizes de inglês-L2 falantes de mandarim-L1, com o objetivo de confirmar a tipologia silábica da L1, atestar as diferenças rítmicas entre mandarim-L1 e inglês-L1, e compreender o processo de aquisição dos 
padrões rítmicos manifestados pela interlíngua. Para tanto, aplicaram as métricas de Ramus, Nespor e Mehler (1999), realizando as medições de $\Delta \mathrm{C}$ e \%V das respectivas L1s e interlíngua. Os resultados confirmaram as diferenças rítmicas entre as L1s tanto em termos de proporção de segmentos vocálicos, com o mandarim apresentando maior proporção, quanto de variação na duração dos intervalos consonantais, com maior variabilidade para o inglês.

Já o comparativo entre ritmo da interlíngua dos aprendizes e o inglês apresentou resultados surpreendentes. Demonstrou-se não haver diferença significativa entre os padrões rítmicos do inglês-L1 e inglês-L2, exceto pela proporção de segmentos vocálicos na situação de leitura de texto, sugerindo que o inglês-L2 de aprendizes falantes de mandarim-L1 aproxima-se mais ritmicamente da L2 que da L1, o que poderia indicar uma correlação entre aquisição do ritmo da L2 e nível de proficiência. O posicionamento do mandarim como língua de ritmo silábico também foi constatado por Ding e Xu (2016) em um estudo comparativo entre mandarim-L1, inglês-L1 e inglês-L2. Os resultados sugerem que a aplicação de métricas duracionais que tomam por referência os segmentos vocálicos figuram como melhores indicadores do ritmo silábico manifestado na realização fonética do inglês-L2 por falantes de mandarim-L1.

Whitworth (2002), por sua vez, realizou um estudo com crianças bilíngues falantes de inglês e alemão para investigar, entre outras questões, se haveria o desenvolvimento de padrões rítmicos diferentes para ambas as línguas, mesmo tratando-se, nesse caso, de línguas consideradas ritmicamente similares, e de que maneira essas produções fonéticas relacionam-se às produções de falantes monolíngues da L1 e da L2. A análise utilizou-se do rPVI-C e nPVI-V. Os resultados sugeriram que as crianças bilíngues são capazes de detectar diferenças rítmicas sutis no input linguístico e são capazes de produzir padrões rítmicos diferenciados, que não necessariamente coincidem com aqueles apresentados por monolíngues, pelo menos do ponto de vista acústico. Os resultados também sugerem que crianças bilíngues passam por uma fase de produção fonética com ritmo mais silábico, mesmo quando expostas a línguas ritmicamente similares e acentuais. O mesmo parece ocorrer em bilíngues expostos a línguas ritmicamente diferentes (BUNTA; INGRAM, 2007; LLÉO; RAKOW; KEHOE, 2007). Essas últimas conclusões dão suporte a outros autores para os quais o percurso do desenvolvimento do ritmo em L2 segue padrões universais ortogonais à L1, indo do silábico ao acentual, independentemente da similaridade rítmica entre L1 e L2.

Essa hipótese foi testada por Ordin e Polyanskaya (2015), que analisaram os padrões rítmicos na realização fonética do inglês-L2 por aprendizes falantes de alemão-L1, 
uma língua ritmicamente similar ao inglês; e francês-L1, ritmicamente dissimilar, com o objetivo de investigar o desenvolvimento rítmico como função do progresso de aquisição da L2. Foram utilizadas métricas rítmicas com base em intervalos vocálicos (nPVI-V, VarcoV), consonantais (nPVI-C e VarcoC), e silábicos (nPVI-S e VarcoS), assim como o cálculo da média de duração silábica (meanS) de cada sentença eliciada por cada falante nos contextos de fala espontânea e não controlada. Análises de Variância (ANOVA) foram implementadas com L1 e nível de proficiência como variáveis preditoras e meanS como variável de resposta. Constatou-se efeito significativo mais robusto entre nível de proficiência e meanS, e não houve interação significativa entre L1 e nível de proficiência, demonstrando taxa de mudança nas durações silábicas similar em ambos os grupos de aprendizes. Outros modelos de regressão implementados nesse estudo demonstraram que tanto a L1 como o nível de proficiência podem exercer efeito sobre as métricas rítmicas.

As investigações sobre a aquisição do ritmo em L2 apresentadas até aqui utilizaram-se de um desenho transversal. Como exemplo de estudo longitudinal do ritmo, White e Mok (2019) investigaram o desenvolvimento rítmico do inglês-L2 de imigrantes de Hong Kong falantes de cantonês-L1 em países falantes de inglês-L1. O estudo também considerou o grau de utilização da L1 e da L2 durante o tempo de estadia no país estrangeiro. Foram utilizadas as métricas de Taxa de Elocução, que corresponde à média do número de unidades articulatórias (segmentos, sílabas, unidades CV) por unidade de tempo (DELLWO, 2008); Varco-C; e PVI-V. Demonstrou-se que o ritmo manifestado na L2 poderia tornar-se mais acentual dentro de certas condições sociais e fonéticas: acomodação da L2, configuração dialetal da população do local de estadia e a demografia da cidade. Tais fatores demonstraram interferir no maior ou menor uso da L2 pelos participantes, afetando o desenvolvimento do ritmo acentual em maior ou menor escala no curso do tempo.

Como exemplo de estudo envolvendo aprendizes falantes de português do Brasil (PB-L1) e inglês-L2, Silva Jr. e Barbosa (2019b) realizaram uma investigação sobre a realização do ritmo do inglês-L2 por falantes de PB-L1 na produção de fala semiespontânea. Foram analisadas métricas e parâmetros acústicos com base em duração e $f_{0}$, e a correlação desses índices com grau de acento. A hipóteses de trabalho era que o ritmo do inglês-L2 apresentaria taxa de elocução mais baixa, devido à falta de fluência; menor variabilidade silábica, pela influência de padrões mais regulares de intervalos silábicos e grupos acentuais; e menor variabilidade de $f_{0}$, em decorrência da atenção mais direcionada a aspectos segmentais que suprassegmentais. Concluiu-se que a produção do inglês-L2 por falantes de PB apresentou grande extensão de vocábulos funcionais, como 
artigos e preposições, e menor extensão de palavras de conteúdo, como substantivos e verbos nas sentenças, o que explica a menor variação silábica. Essa dificuldade de reduzir apropriadamente vocábulos funcionais desfavorece a implementação de maior grau de ritmo acentual por falantes de PB, característico do inglês.

Percebe-se que o estudo do ritmo no âmbito do desenvolvimento de L2 oferece muitas possibilidades de investigação. São poucos os trabalhos no âmbito do ritmo que investigam aprendizes de L2, e em menor número ainda são os trabalhos que investigam falantes de PB-L1 aprendizes de inglês-L2. Constata-se uma lacuna para estudos que consideram o desenvolvimento do ritmo da L2 em função do ensino explícito de pronúncia, e em uma perspectiva longitudinal. Tais considerações demonstram o caráter oportuno deste estudo e de seu relatório preliminar, em um campo ainda pouco explorado do componente fonético-fonológico no desenvolvimento de L2.

O objetivo geral do projeto de pesquisa guarda-chuva que abriga este relato preliminar é descrever o desenvolvimento do ritmo do inglês-L2 por aprendizes brasileiros por meio de métricas rítmicas e parâmetros acústicos que caracterizam a produção oral desses aprendizes em diferentes etapas do desenvolvimento da L2, em uma perspectiva multidimensional. Neste artigo, fazemos uma análise preliminar, discutindo o desenvolvimento do ritmo do inglês-L2 por aprendizes brasileiros por meio das três principais métricas utilizadas até então: \%V e $\Delta \mathrm{C}$, PVIs, e Varcos. Para tanto, analisamos dados de produção oral de alunos brasileiros de graduação em Letras-Inglês lendo um texto em português e lendo um texto em inglês em dois momentos distintos, antes e após cursarem duas disciplinas sobre a fonologia do inglês. Também foram analisados dados de falantes nativos de inglês norte-americano lendo o mesmo texto. Trata-se de uma análise preliminar uma vez que os próximos passos do projeto guarda-chuva envolvem analisar os mesmos dados, bem como outras duas gravações de inglês-L2 intermediárias que foram coletadas, com outras métricas rítmicas, com parâmetros acústicos, e como sistema dinâmico de osciladores acoplados (BARBOSA, 2006).

Buscamos, por meio da presente análise, responder às seguintes perguntas: (i) Como as métricas $\Delta \mathrm{C}-\% \mathrm{~V}$, VarcoC-VarcoV, e rPVI-C-nPVI-V posicionam o inglês-L1 norte-americano, o inglês-L2 de brasileiros, e o PB-L1 em seus espaços rítmicos? (ii) Qual é o efeito do ensino explícito de pronúncia no desenvolvimento do ritmo do inglês-L2 dos aprendizes? (iii) Qual é a influência do ritmo do PB-L1 no desenvolvimento do inglês-L2 dos aprendizes? A hipótese de trabalho básica é de que o PB-L1, o inglês-L1 e o inglês-L2 são ritmicamente diferentes, o que será capturado pelas métricas rítmicas empregadas. Além disso, haverá diferenças rítmicas entre o inglês-L2 dos falantes nas duas diferentes 
etapas do desenvolvimento cujas gravações foram analisadas. Espera-se também que as métricas rítmicas da primeira gravação dos aprendizes sejam mais dissimilares ao inglês-L1 devido à ausência de instrução explícita e aos processos fonológicos do PB, que tendem a ser transferidos para o inglês-L2.

\section{MÉTODO}

Nesta seção, são apresentados os participantes, os materiais e os procedimentos empregados neste estudo.

\section{Participantes}

Os participantes que compõem o grupo experimental perfazem um total de cinco aprendizes, estudantes universitários de Letras-Inglês, sendo quatro homens e uma mulher, com idade entre 18 e 24 anos. Os critérios para participação na pesquisa incluíam: a) não possuir trancamento ou reprovação no curso; b) não ter viajado para país falante de língua inglesa; e c) nunca ter tido contato contínuo com falante nativo de língua inglesa. Todos os alunos ingressantes foram convidados a contribuir com gravações semestrais a partir do início do segundo semestre de estudos, porém alguns aprendizes foram desistindo de participar das coletas, ou não se encaixavam mais nos critérios, de modo que houve apenas cinco participantes na última gravação, os quais integram este estudo. O grupo controle é composto por cinco falantes de inglês-L1, canadenses, com idades entre 23 e 34 anos, sendo um homem e quatro mulheres. A coleta de dados foi autorizada pelo Comitê de Ética em Pesquisa (CAAE: 40985414.1.0000.5054) e os participantes assinaram um Termo de Consentimento Livre Esclarecido.

\section{Materiais}

Integram este estudo quatro corpora de produção oral: inglês-L1, PB-L1, inglês-L2 (1) e inglês-L2 (4). Os dados do inglês-L2 foram obtidos por meio de gravações dos aprendizes brasileiros lendo o primeiro parágrafo do texto diagnóstico de Celce-Murcia et al. (2010) em dois momentos distintos, antes e depois de os alunos cursarem as disciplinas Fonologia Segmental da Língua Inglesa, no terceiro semestre da graduação; e Fonologia Suprassegmental da Língua Inglesa, no quarto semestre. Trata-se da primeira e da quarta gravação realizadas, por isso são chamadas aqui de inglês-L2 (1) e inglês-L2 (4). Os dados do inglês-L1 foram obtidos por meio da leitura do mesmo texto pelos integrantes 
do grupo controle. Os dados do português-L1 são provenientes da leitura realizada pelos cinco aprendizes brasileiros de uma versão traduzida para o português do mesmo texto (Anexos A e B). Ambas as versões do texto contêm sete sentenças, incluindo orações simples e complexas, declarativas afirmativas, e interrogativas abertas e fechadas.

\section{Procedimentos}

Os participantes foram gravados individualmente em uma sala silenciosa, uma vez por semestre por quatro semestres consecutivos. As gravações foram realizadas com um microfone de lapela supercardioide Shure 150B, conectado a um gravador Zoom Hn4. O áudio foi capturado em mono, com taxa de amostragem de $44 \mathrm{kHz}$ e posteriormente salvo em formato wav. Para a análise acústica e extração das métricas rítmicas no PRAAT (BOERSMA; WEENINK, 2020), os dados foram segmentados manualmente em vogais e consoantes para este estudo, além da segmentação em sílabas fonéticas (unidades VV, onset de uma vogal até o onset da próxima vogal), sentenças e unidades sintáticoprosódicas (chunks) para etapas futuras de análise. Para a extração das métricas, foi utilizado o script Metrics\&AcousticsExtractor (SILVA JR.; BARBOSA, 2019a).

\section{RESULTADOS}

A tabela 1 apresenta as médias das métricas para os dados de PB, inglês-L1, inglês-L2 (1) e inglês-L2 (4).

Tabela 1: Médias absolutas de $\% \mathrm{~V}, \Delta \mathrm{C}$, VarcoV, VarcoC, nPVI-V e rPVI-C para PB, inglês-L1, inglês-L2 (1) e inglês-L2

\begin{tabular}{ccccccc}
\hline Língua & $\mathbf{\% V}$ & $\boldsymbol{\Delta} \mathbf{C}$ & VarcoV & VarcoC & nPVI-V & rPVI-C \\
\hline PB & 48,56 & 46,48 & 49,04 & 49,84 & 62,4 & 48,22 \\
Inglês-L1 & 38,88 & 68,41 & 54,8 & 59 & 66,92 & 86,16 \\
Inglês-L2 (1) & 36,24 & 105,19 & 58,8 & 66,8 & 70,76 & 116,84 \\
Inglês-L2 (4) & 39,28 & 84,08 & 56,32 & 59,72 & 63,4 & 88,70 \\
\hline
\end{tabular}

Fonte: autores.

Conforme pode ser observado na tabela 1, o PB registrou os menores valores para todas as métricas, à exceção de \%V, evidenciando uma tendência ao ritmo mais 
silábico. O contrário ocorreu com os dados do inglês-L2(1) que, também à exceção de $\% \mathrm{~V}$, registraram os valores mais extremos para os índices métricos analisados. Já os dados do inglês-L2(4) aproximam-se mais do inglês-L1, cujos valores figuram como intermediários entre inglês-L2(4) e PB, à exceção de nPVI-C. Nas próximas seções, esses resultados serão apresentados em forma de gráficos bidimensionais.

$\Delta \mathrm{C}$ e $\% \mathrm{~V}$

O gráfico a seguir (figura 2) apresenta a distribuição dos quatro corpora deste estudo em um plano cartesiano com $\Delta \mathrm{C}$ e $\% \mathrm{~V}$ nos eixos, como realizado por Ramus, Nespor e Mehler (1999):

Figura 2: Inglês-L1, inglês-L2 (1), inglês-L2 (4) e PB no plano formado pelos eixos $\Delta \mathrm{C}$ e \%V.

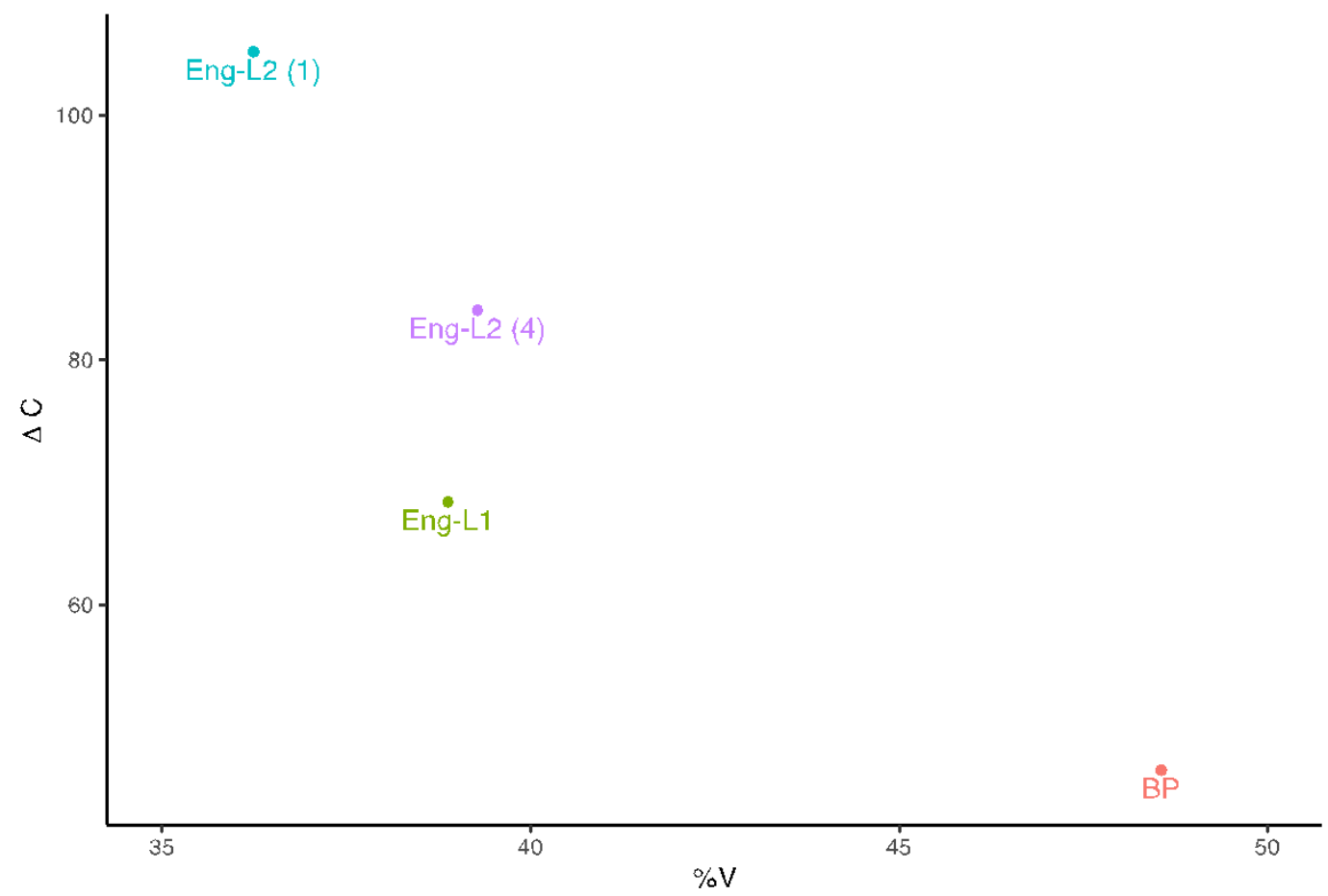

Fonte: Autores.

No plano rítmico criado pelos eixos $\Delta \mathrm{C}$ e \% $\mathrm{V}$, inglês-L1, inglês-L2 (1), inglês-L2 (4) e PB ocuparam posições claramente distintas. Em relação aos dados de L1, inglês-L1 e PB ocuparam posições opostas em relação aos eixos $\Delta \mathrm{C}$ e \% . O inglês-L1 apresentou maior desvio-padrão da duração de intervalos consonantais $(\Delta \mathrm{C}=68,41)$ em comparação 
ao PB $(46,48)$; e o PB apresentou maior proporção do enunciado composto de intervalos vocálicos $(\% \mathrm{~V}=48,56)$ em comparação ao inglês-L1 $(38,88)$. Os dados de inglês-L2 se posicionaram distantes das duas línguas nativas, com o inglês-L2 (1) ocupando uma posição no plano rítmico diametralmente oposta ao PB e distante também do inglês-L1, registrando valores de $\Delta \mathrm{C}$ bastante elevados $(105,19)$ e a menor proporção de segmentos vocálicos $(\% \mathrm{~V}=36,24)$ dentre os quatro corpora analisados. O inglês-L2 (4) aproximouse do inglês-L1 em relação ao eixo $\Delta \mathrm{C}(84,08)$ e registrou valores bem próximos ao inglês-L1 para o eixo \%V $(39,28)$, indicando um percurso de desenvolvimento dos aprendizes rumo a padrões prosódicos mais próximos do inglês-L1.

Dois modelos de regressão de efeitos mistos (com intercepts aleatórios para participantes e chunks) foram ajustados, um para cada métrica, e ambos revelaram efeitos significativos de cada uma das (inter)línguas sobre as métricas, conforme mostra o resumo dos modelos da tabela 2 .

Tabela 2: Coeficientes, intervalos de confiança (95\%) e valores de p para os dois modelos de regressão linear com efeitos mistos ajustados para $\Delta \mathrm{C}$ e $\% \mathrm{~V}$. Modelos: deltaC $\sim$ Lang + $(1 \mid$ Chunk $)+(1 \mid$ Speaker $)$ e percV $\sim$ Lang $+(1 \mid$ Chunk $)+(1 \mid$ Speaker $)$.

\begin{tabular}{cccccccc}
\hline & \multicolumn{3}{|c|}{$\boldsymbol{\Delta C}$} & \multicolumn{3}{c}{$\mathbf{\% V}$} \\
\hline Predictors & Estimates & $C I$ & $p$ & Estimates & $C I$ & $p$ \\
\hline (Intercept) & 46.48 & $36.17-56.79$ & $<\mathbf{0 . 0 0 1}$ & 48.78 & $46.02-51.55$ & $<\mathbf{0 . 0 0 1}$ \\
Lang [Eng-L1] & 21.94 & $7.35-36.52$ & $\mathbf{0 . 0 0 4}$ & -9.66 & $-12.97--6.35$ & $<\mathbf{0 . 0 0 1}$ \\
Lang [Eng-L2 (1)] & 58.71 & $44.13-73.30$ & $<\mathbf{0 . 0 0 1}$ & -11.92 & $-14.23--9.61$ & $<\mathbf{0 . 0 0 1}$ \\
Lang [Eng-L2 (4)] & 37.61 & $23.02-52.19$ & $<\mathbf{0 . 0 0 1}$ & -9.28 & $-11.47--7.09$ & $<\mathbf{0 . 0 0 1}$ \\
\hline
\end{tabular}

Fonte: Autores. 
Comparando os dados deste estudo aos do estudo seminal de Ramus, Nespor e Mehler (1999), obtemos a distribuição da figura 3:

Figura 3: Dados do presente estudo e dos de Ramus, Nespor e Mehler (1999) para $\Delta \mathrm{C}$ e $\% \mathrm{~V}$, em que Eng $=$ inglês, $\mathrm{Pol}=$ polonês, Dut $=$ holandês, $\mathrm{Spa}=$ espanhol, Fre $=$ francês, $\mathrm{Ita}=$ italiano, Cat $=$ catalão, Jap $=$ japonês.

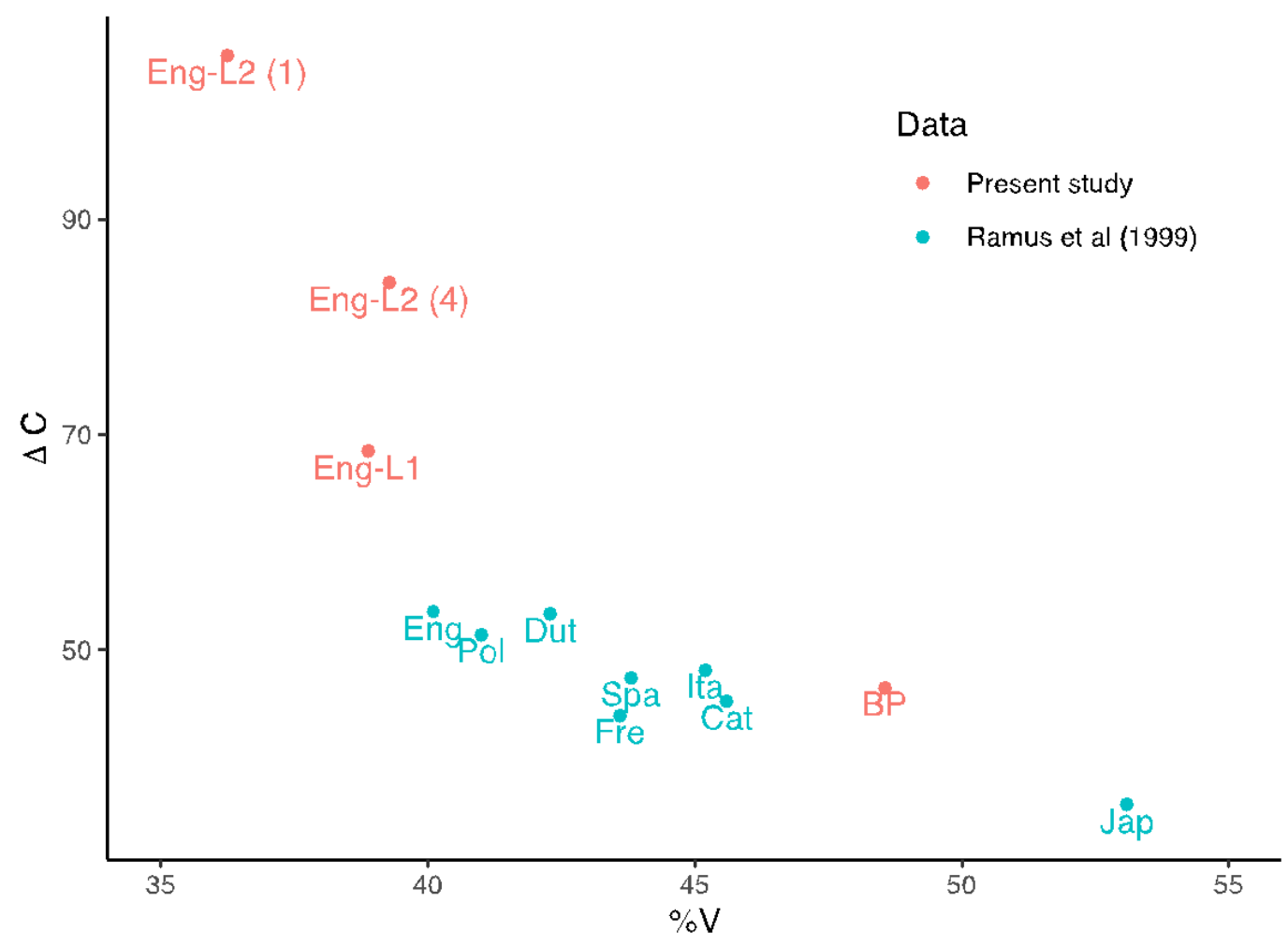

Fonte: Autores.

Os dados de PB aproximaram-se dos de línguas de ritmo considerado prototipicamente mais silábico (espanhol, italiano, francês e catalão), com valores muito próximos sobretudo no eixo de $\Delta \mathrm{C}$. Em relação ao eixo \%V, o PB registrou a segunda maior proporção vocálica dentre todas as línguas consideradas no comparativo, apontando para uma maior tendência ao ritmo silábico. Percebe-se, contudo, um distanciamento do PB em relação ao japonês, de ritmo supostamente moraico. Semelhantemente, os dados de inglês-L1 se aproximaram dos das línguas de ritmo prototipicamente acentual (inglês, polonês e holandês), principalmente no eixo de \%V. As diferenças verificadas no eixo $\Delta \mathrm{C}$ podem estar relacionadas às variedades dialetais utilizadas neste estudo, inglêsnorte americano canadense, e em Ramus, Nespor e Mehler (1999), não especificada; 
ou a diferentes taxas de elocução, conforme assevera Dellwo (2006). As interlínguas se posicionaram distantes das demais línguas, em direção ao ritmo acentual, mas com os dados do inglês-L2 (4) se aproximando mais dos dados de inglês-L1 deste estudo e dos de Ramus, Nespor e Mehler (1999), principalmente em relação ao eixo \%V.

Como forma de mais uma comparação, apresentamos (figura 4) os nossos dados em meio aos dados resenhados ${ }^{7}$ e obtidos por Arvaniti (2012), cujo estudo abrangente incluiu um total de seis línguas, sendo duas consideradas prototipicamente mais acentuais (inglês e alemão), duas consideradas de ritmo mais silábico (espanhol e italiano), e duas consideradas até então de difícil classificação (grego e coreano).

Figura 4: Dados do presente estudo (azul escuro) em meio a todos os dados resenhados e obtidos por Arvaniti (2012) (azul claro) para $\Delta \mathrm{C}$ e \%V, em que Eng = inglês, Ger = alemão, Gre $=$ grego, $\mathrm{Spa}=$ espanhol, Ita $=$ italiano, Kor $=$ coreano.

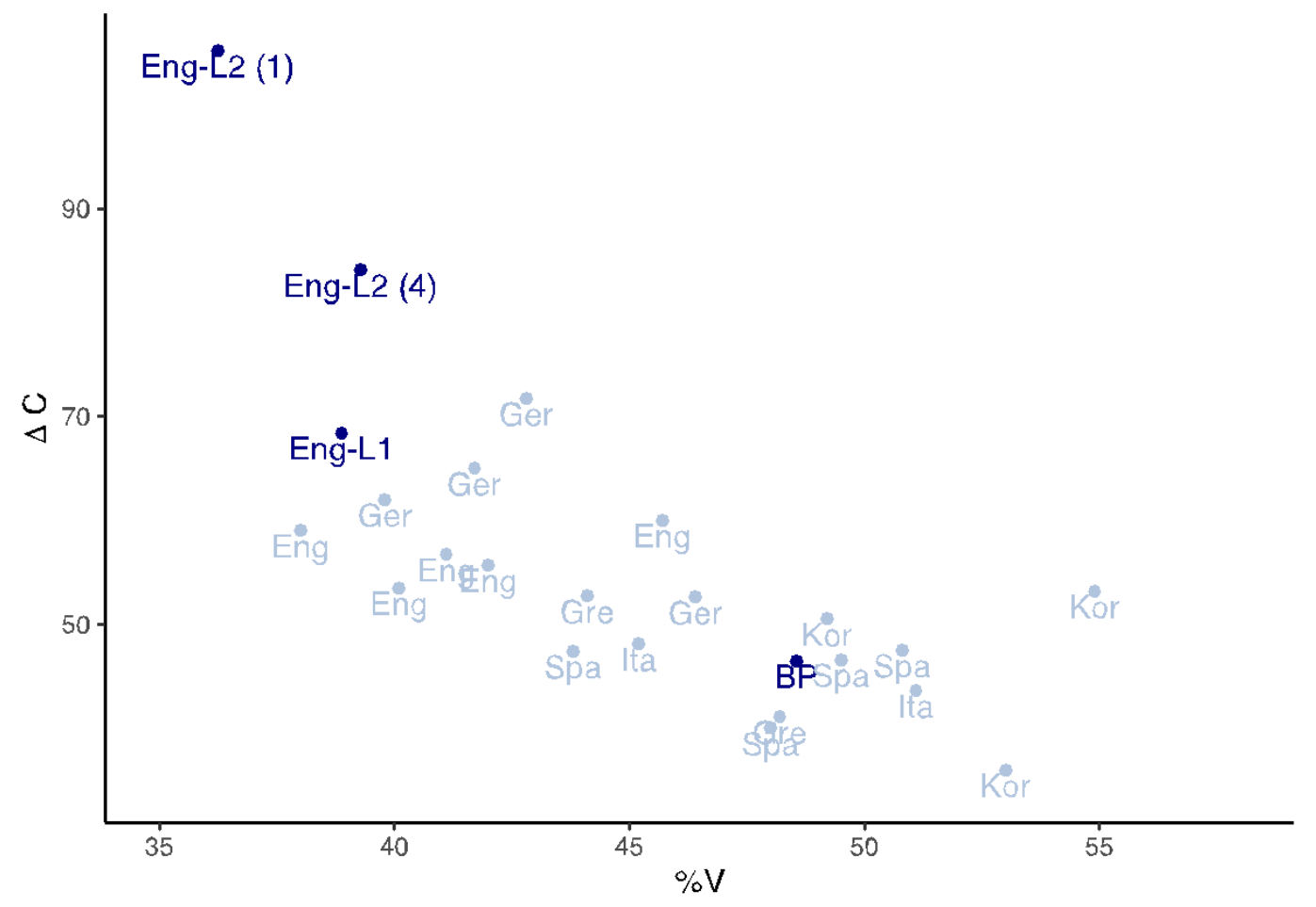

Fonte: Autores.

\footnotetext{
${ }^{7}$ Especificamente, os dados de Baltazani (2007); Dellwo e Wagner (2003); Grabe e Low (2002); Jeon (2006); Mok e Lee (2008); Ramus, Nespor e Mehler (1999); Russo e Barry (2008); Tisiartsioni (2003); e White e Mattys (2007).
} 
A análise visual desses agrupamentos no plano $\Delta \mathrm{C}-\% \mathrm{~V}$ permite confirmar mais uma vez a peculiaridade temporal do inglês-L2 (1), que se afasta diametralmente do PB e registra os valores mais extremos para ambos os eixos dentre todas as línguas reportadas. Já os dados do inglês-L2 (4) aproximam-se dos dados de línguas consideradas mais acentuais, ocupando uma posição mais consistente e intermediária para o eixo \% em relação às médias registradas para o inglês e o alemão nos estudos de referência. Os dados do inglês-L1 reportados neste estudo parecem consistentes em relação à literatura em ambos os eixos, embora com maior variação no eixo $\Delta \mathrm{C}$. Os dados do PB agrupamse aos de línguas consideradas de ritmo mais silábico, aproximando-se do espanhol e do italiano no eixo $\Delta \mathrm{C}$, e do espanhol, do grego e do coreano no plano $\% \mathrm{~V}$.

\section{VarcoC e VarcoV}

A figura 5 apresenta a distribuição dos corpora deste estudo para VarcoC, coeficiente de variação da duração de intervalos consonantais; e VarcoV, coeficiente de variação da duração de intervalos vocálicos.

Figura 5: Inglês-L1, inglês-L2 (1), inglês-L2 (4) e PB no plano formado pelos eixos VarcoC e VarcoV.

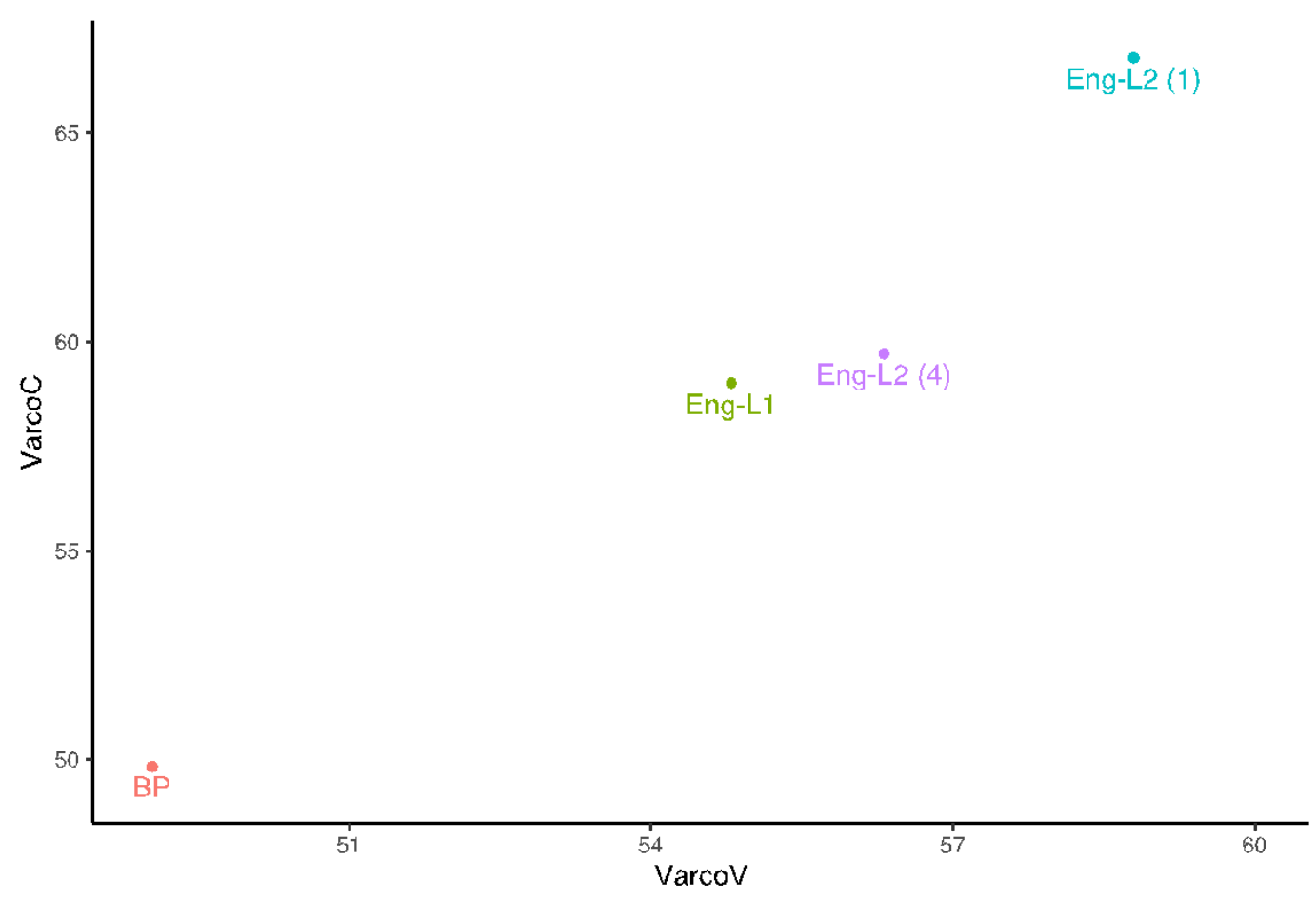

Fonte: Autores. 
Note-se, primeiramente, que, no plano com $\Delta \mathrm{C}$ e $\% \mathrm{~V}$ nos eixos y e $\mathrm{x}$, respectivamente, as línguas se posicionam do canto superior esquerdo representando as mais acentuais para o canto inferior direito representando as mais silábicas. Num plano com VarcoC e VarcoV nos mesmos eixos, as línguas se posicionam numa diagonal inversa, com as línguas mais acentuais em direção ao canto superior direito, onde há maior variabilidade nas durações tanto de vogais como de consoantes; e as línguas mais silábicas em direção ao canto inferior esquerdo, onde há menor variabilidade (maior estabilidade) nas durações dos intervalos consonantais e vocálicos.

Sendo assim, observamos que, no plano rítmico formado pelos eixos VarcoC e VarcoV, inglês-L1, inglês-L2 (1), inglês-L2 (4) e PB distribuíram-se de maneira análoga ao plano $\Delta \mathrm{C}$ e $\% \mathrm{~V}$, com os dados do $\mathrm{PB}$ registrando menor índice de variabilidade tanto em relação ao eixo VarcoC $(49,84)$ como ao de VarcoV $(49,04)$. Os dados de interlíngua e inglês-L1 também apresentaram consistência em relação aos resultados obtidos para $\Delta \mathrm{C}$ e \%V. O inglês-L2 (1) apresentou as maiores pontuações tanto no eixo VarcoC $(66,8)$ quanto em relação ao eixo VarcoV $(58,8)$. Já o inglês-L2 (4) registrou valores mais baixos para VarcoC $(59,72)$ e VarcoV $(56,32)$, muito próximos aos valores do inglês-L1, que apresentou as segundas menores médias para VarcoC (59) e VarcoV (54,8). Apesar de a hierarquia de valores para VarcoV e VarcoC ter sido análoga ao plano $\Delta \mathrm{C}$ e \%V ([+ acentual] inglês-L2 (1) > inglês-L2 (4) > inglês-L1 > PB [+ silábico]), observamos que o inglês-L2 (4) ficou posicionado ainda mais próximo ao inglês-L1 com essas métricas.

Dois modelos de regressão de efeitos mistos (com intercepts aleatórios para participantes e chunks) foram ajustados, um para cada métrica, e ambos revelaram efeitos significativos das (inter)línguas sobre as métricas, com exceção de inglês-L1 em comparação ao PB para VarcoV, conforme mostra o resumo dos modelos da tabela 3.

Tabela 3: Coeficientes, intervalos de confiança (95\%) e valores de p para os dois modelos de regressão linear com efeitos mistos ajustados para VarcoC e VarcoV. Modelos: varcoC $\sim$ Lang +

$(1 \mid$ Chunk $)+(1 \mid$ Speaker $)$ e varcoV $\sim$ Lang $+(1 \mid$ Chunk $)+(1 \mid$ Speaker $)$

\begin{tabular}{cccccccc}
\hline & \multicolumn{3}{|c|}{ varcoC } & \multicolumn{3}{c}{ varcoV } \\
\hline Predictors & Estimates & $C I$ & $p$ & Estimates & $C I$ & $p$ \\
\hline (Intercept) & 49.84 & $44.01-55.67$ & $<\mathbf{0 . 0 0 1}$ & 48.20 & $41.98-54.41$ & $<\mathbf{0 . 0 0 1}$ \\
Lang [Eng-L1] & 9.16 & $0.91-17.41$ & $\mathbf{0 . 0 3 0}$ & 6.60 & $-2.20-15.40$ & $\mathbf{0 . 1 4 1}$ \\
Lang [Eng-L2 (1)] & 16.96 & $8.71-25.21$ & $<\mathbf{0 . 0 0 1}$ & 10.83 & $4.52-17.13$ & $\mathbf{0 . 0 0 1}$ \\
Lang [Eng-L2 (4)] & 9.88 & $1.63-18.13$ & $\mathbf{0 . 0 1 9}$ & 7.28 & $1.27-13.29$ & $\mathbf{0 . 0 1 8}$ \\
\hline
\end{tabular}

Fonte: Autores 
Para efeito de comparação, apresentamos, na figura 6, os dados obtidos neste estudo em meio aos resultados resenhados e obtidos por Arvaniti (2012) para VarcoC e VarcoV:

Figura 6: Dados do presente estudo em meio a todos os dados resenhados e obtidos por Arvaniti (2012) para VarcoC e VarcoV, em que Eng = inglês, Ger = alemão, Gre = grego, Spa = espanhol, Ita $=$ italiano, Kor $=$ coreano.

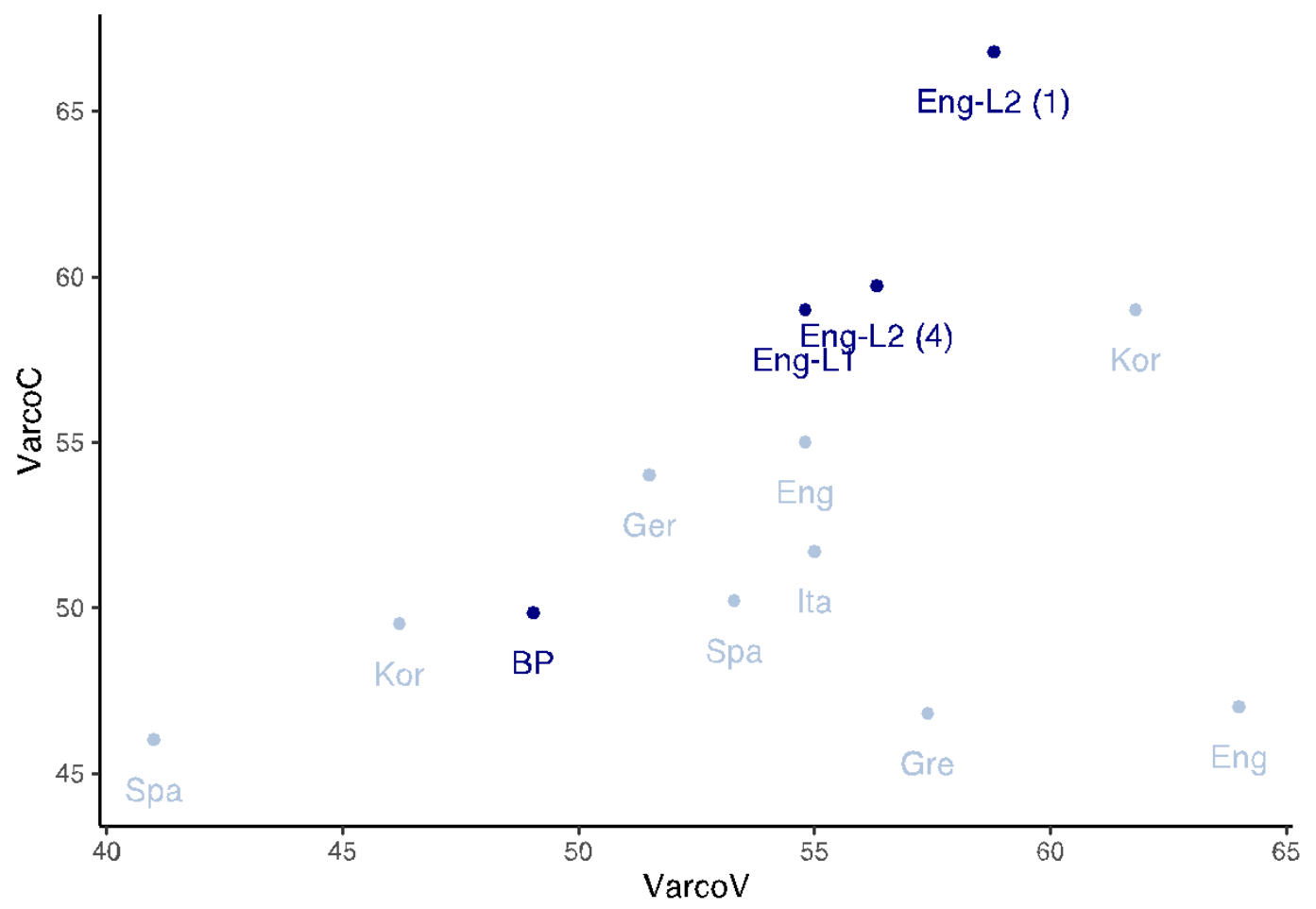

Fonte: Autores.

Os dados de PB aproximaram-se dos de línguas consideradas prototipicamente mais silábicas (espanhol e italiano). Em relação ao inglês-L1, a média obtida para VarcoC ficou um pouco acima da média dos dados do inglês obtidos por Arvaniti (2012), mas o valor de VarcoV foi exatamente o mesmo nos dados deste estudo e nos dados obtidos por Arvaniti. Há uma ocorrência de inglês com valores bastante baixos para VarcoC, obtidos por White e Mattys (2007). As interlínguas se posicionaram como sendo ainda mais acentuais, mas com os dados da quarta gravação se aproximando bastante dos dados de inglês-L1. 


\section{rPVI-C e nPVI-V}

O gráfico da figura 7 apresenta a distribuição dos resultados dos quatro corpora deste estudo obtidos pelas métricas rPVI-C e nPVI-V:

Figura 7: Inglês-L1, inglês-L2(1), inglês-L2(4) e PB no plano formado pelos eixos rPVI-C e nPVI-V.

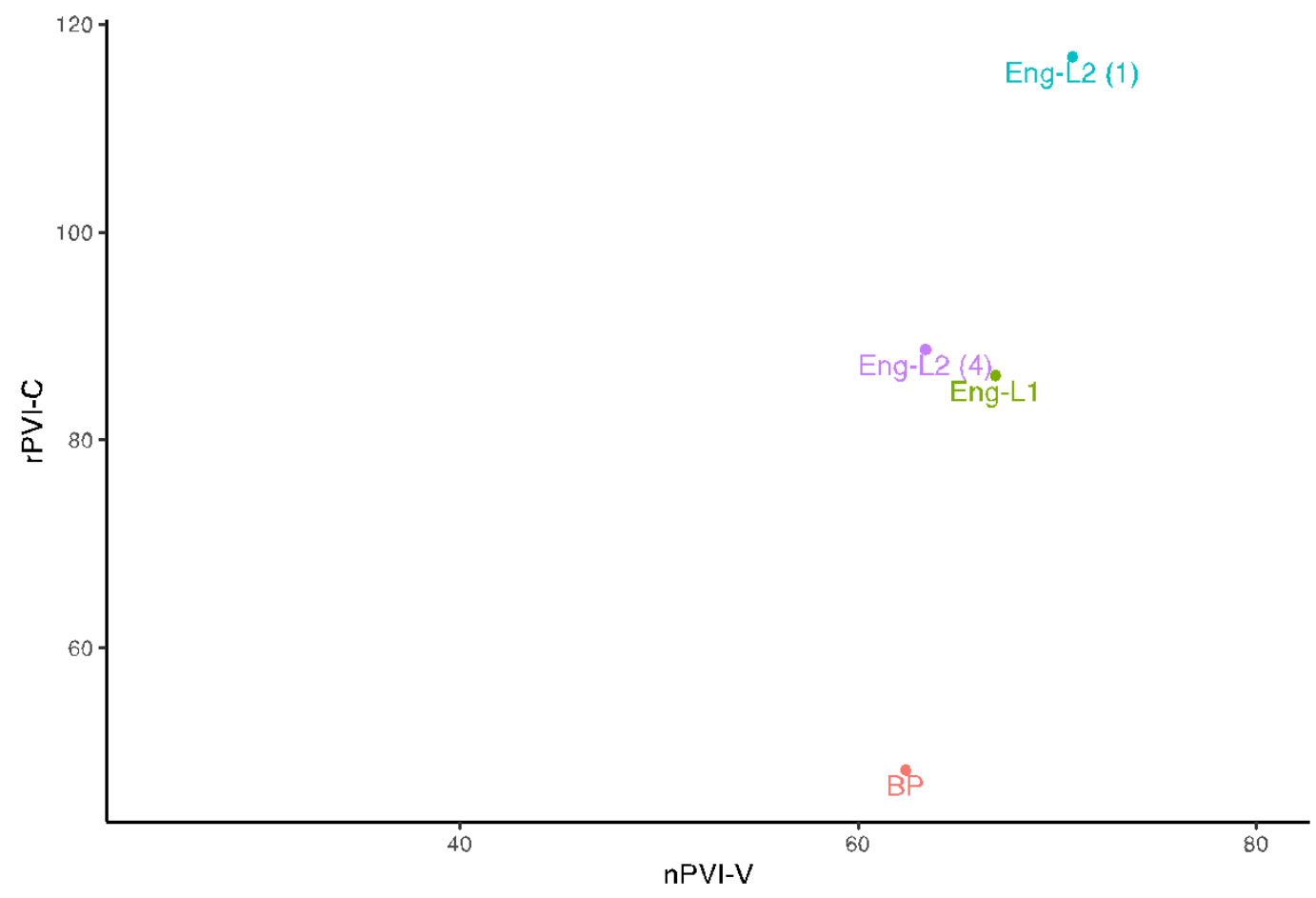

Fonte: Autores.

No plano formado pelos eixos rPVI-C e nPVI-V, inglês-L1, inglês-L2 (1), inglês-L2 (4) e PB também assumiram posições distintas, embora as maiores distâncias tenham sido registradas no eixo rPVI-C (rPVI-C $\mathrm{PB}_{\mathrm{PB}}=48,22 ; \mathrm{rPVI} \mathrm{C}_{\text {inglês-L1 }}=86,16$; rPVI-C $_{\text {inglês-L2(1) }}=116,84$; rPVI-C inglês-L2(4) $=88,70$ ), com PB e inglês-L2(1) mais uma vez ocupando posições diametralmente opostas, e inglês-L1 e inglês-L2(4) ocupando posições intermediárias e muito próximas, indicando um percurso de desenvolvimento rumo aos padrões prosódicos da língua não nativa, pelo menos em relação à variabilidade 
dos intervalos consonantais adjacentes. Já em relação ao eixo nPVI-V, os resultados são menos elucidativos, embora os dados indiquem uma maior tendência ao ritmo silábico para o PB (nPVI-V = 62,4) em comparação aos dados do inglês-L1 (nPVI-V = 66,92) e aos dados de interlíngua (nPVI- $\left.\mathrm{V}_{\text {inglês-L2(1) }}=70,76 ; \mathrm{nPVI}^{-\mathrm{V}_{\text {inglês-L2(4) }}}=63,4\right)$.

Dois modelos de regressão de efeitos mistos (com intercepts aleatórios para participantes e chunks) foram ajustados, um para cada métrica. O modelo para rPVI-C revelou efeitos significativos de cada uma das (inter)línguas sobre a métrica. O modelo de nPVI-V, no entanto, apresentou efeito apenas para a primeira gravação de inglês-L2 em relação ao $\mathrm{PB}$, conforme mostra o resumo dos modelos da tabela 4.

Tabela 4: Coeficientes, intervalos de confiança (95\%) e valores de p para os dois modelos de regressão linear com efeitos mistos ajustados para rPVI-C e nPVI-V. Modelos: rPVIC $\sim$ Lang + $(1 \mid$ Chunk $)+(1 \mid$ Speaker $)$ e nPVIV $\sim$ Lang $+(1 \mid$ Chunk $)+(1 \mid$ Speaker $)$.

\begin{tabular}{cccccccc}
\hline & \multicolumn{3}{|c|}{ rPVIC } & \multicolumn{3}{c}{ nPVIV } \\
\hline Predictors & Estimates & $C I$ & $p$ & Estimates & $C I$ & $p$ \\
\hline (Intercept) & 48.09 & $34.98-61.20$ & $<\mathbf{0 . 0 0 1}$ & 61.23 & $55.38-67.08$ & $<\mathbf{0 . 0 0 1}$ \\
Lang [Eng-L1] & 38.40 & $21.81-55.00$ & $<\mathbf{0 . 0 0 1}$ & 5.27 & $-2.15-12.69$ & $\mathbf{0 . 1 6 4}$ \\
Lang [Eng-L2 (1)] & 69.07 & $53.98-84.16$ & $<\mathbf{0 . 0 0 1}$ & 8.99 & $4.04-13.95$ & $<\mathbf{0 . 0 0 1}$ \\
Lang [Eng-L2 (4)] & 40.48 & $25.68-55.28$ & $<\mathbf{0 . 0 0 1}$ & 1.00 & $-3.69-5.69$ & $\mathbf{0 . 6 7 6}$ \\
\hline
\end{tabular}

Fonte: Autores.

Os dados obtidos neste estudo para rPVI-C e nPVI-V foram comparados, primeiramente, aos resultados reportados por Grabe e Low (2002), quando fizeram a proposta das métricas, conforme figura 8 . 
Figura 8: Dados do presente estudo e dos de Grabe e Low (2002) para rPVI-C e nPVI-V.

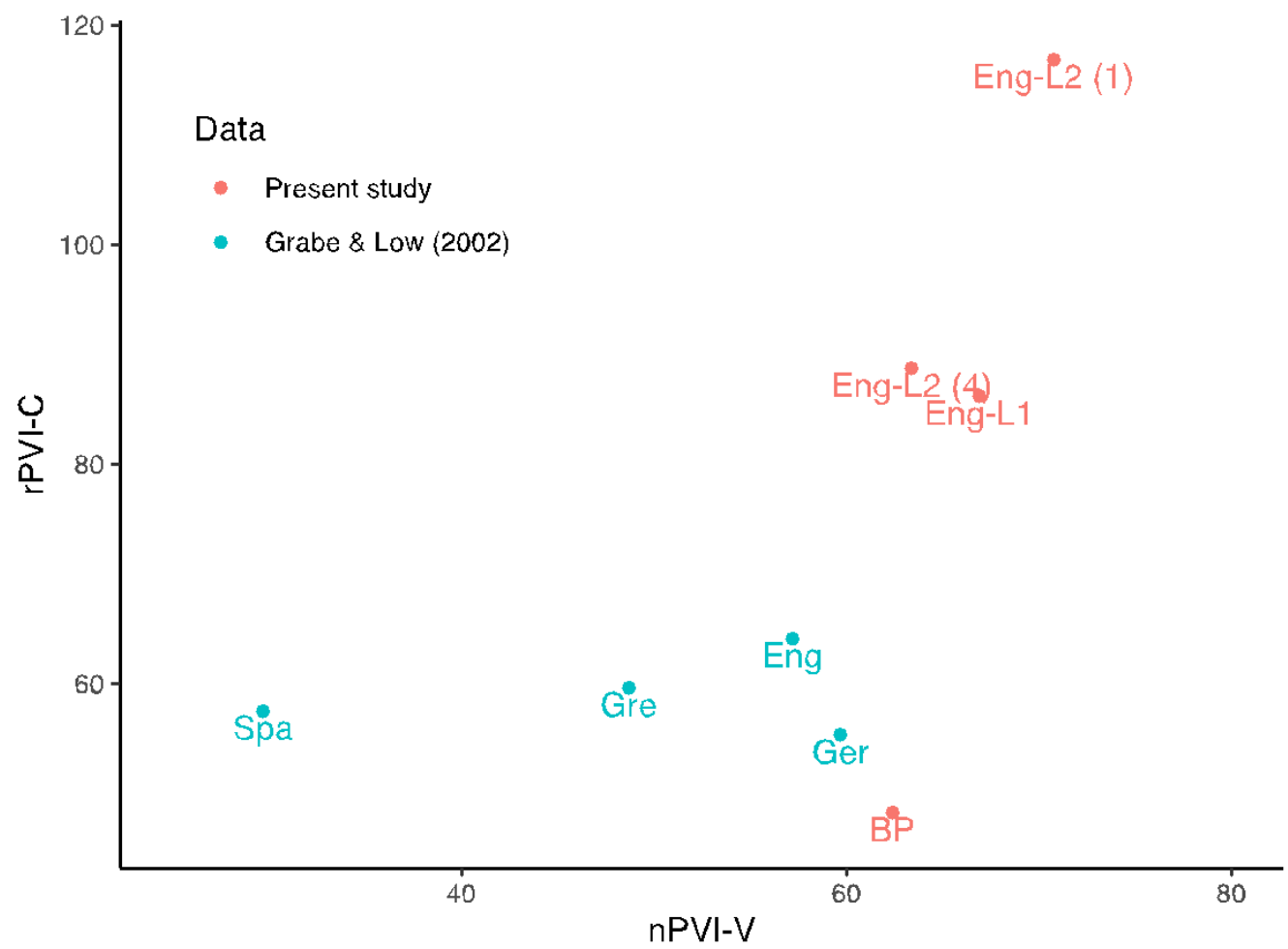

Fonte: Autores.

Os resultados deste estudo para $\mathrm{nPVI}-\mathrm{V}$ foram maiores do que os encontrados por Grabe e Low (2002), distanciando-se, principalmente, dos dados do grego e do espanhol. Como, em teoria, valores menores de nPVI-V são esperados para línguas de ritmo mais silábico, o comparativo entre os dois estudos mostrou-se inconsistente. Já em relação ao eixo rPVI-C, o PB registrou o menor valor dentre todas as línguas em ambos os estudos, e as interlínguas, seguidas pelo inglês-L1, os maiores valores.

Para uma comparação ainda mais completa, apresentamos os dados deste estudo em meio a todos os dados resenhados e obtidos por Arvaniti (2012) na figura 9: 
Figura 9: Dados do presente estudo (azul escuro) em meio a todos os dados resenhados e obtidos por Arvaniti (2012) (azul claro) para rPVI-C e nPVI-V, em que Eng = inglês, Ger = alemão, Gre $=$ grego, $\mathrm{Spa}=$ espanhol, $\mathrm{Ita}=$ italiano, Kor $=$ coreano.

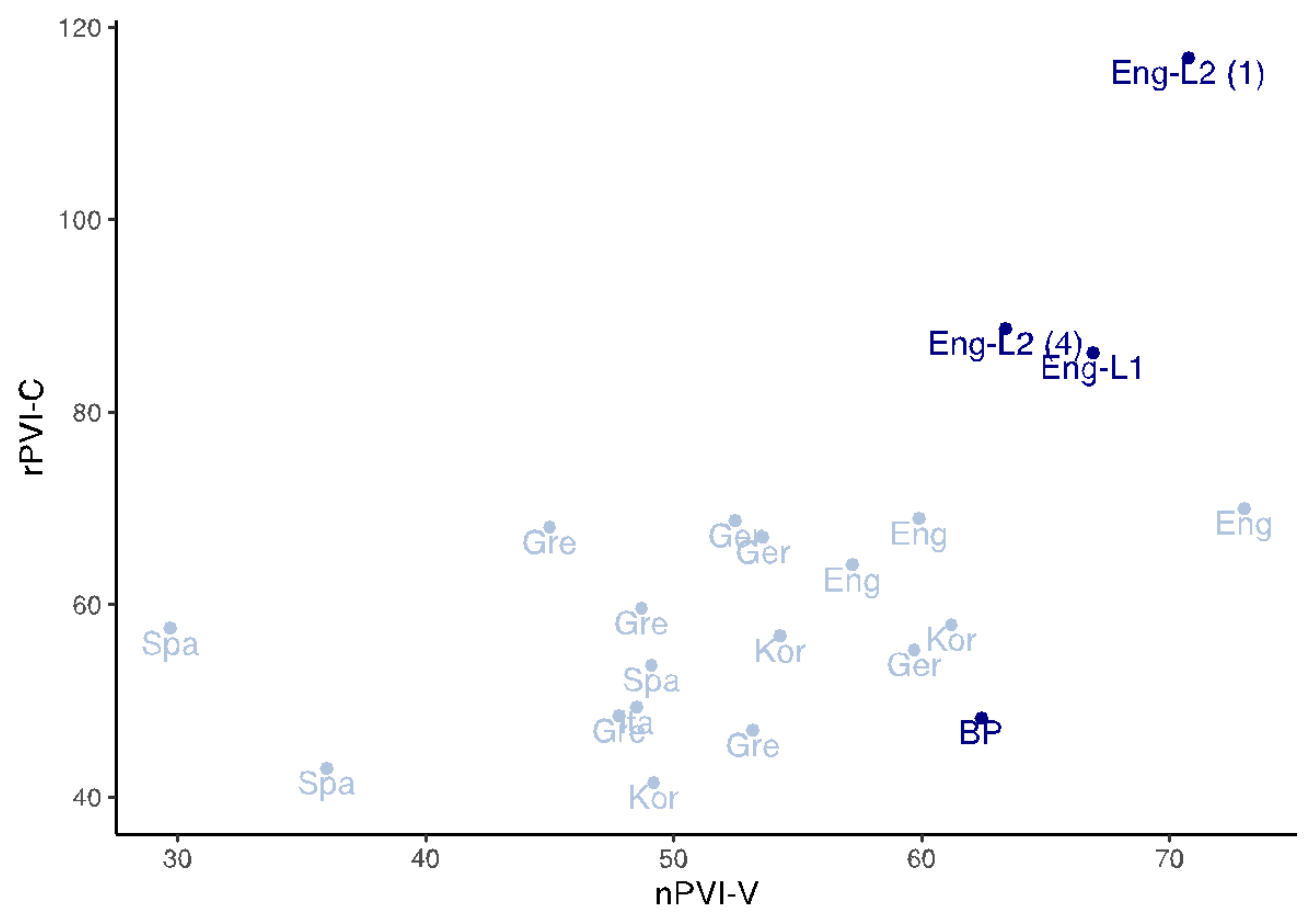

Fonte: Autores.

Os dados do inglês-L2 (1) despontam como os mais extremos no eixo nPVI-C e com a segunda maior média para nPVI-V, menor apenas que a média reportada por White e Mattys (2007). Em seguida, tanto os valores do inglês-L1 quanto do inglês-L2 (4), que se aproximam bastante em ambos os eixos, registram valores mais elevados em relação a todas as demais línguas. Já o PB agrupa-se com línguas como o grego e o italiano no eixo rPVI-C, mas se distancia delas em nPVI-V, apresentando o quinto maior valor nesse eixo.

\section{Distâncias euclidianas}

Um aspecto de interesse para os objetivos deste estudo era verificar o posicionamento do PB, do inglês-L1, do inglês-L2 (1) e do inglês-L2 (4) nos planos rítmicos formados pelos pares $\Delta \mathrm{C}-\% \mathrm{~V}$, VarcoC-VarcoV e rPVI-C-nPVI-V. A fim de se contabilizar a distância entre as interlínguas e o inglês-L1 em cada plano rítmico, calculamos, em cada um deles, as distâncias euclidianas entre inglês-L1 e as interlínguas, bem como entre as PB-L1 e inglês-L1 para fins de comparação. A distância euclidiana é um cálculo de dissimilaridade, que é basicamente a soma das diferenças, e que pode 
ser utilizado para medir a distância entre dois pontos em um plano cartesiano, como os formados pelos pares de métricas. Neste caso, foram calculadas com:

$$
\begin{gathered}
\left(y_{\text {Ling } 1}-y_{\text {Ling } 2}\right)^{2}+\left(x_{\text {Ling } 1}-x_{\text {Ling } 2}\right)^{2} \\
\text { onde } x \text { e } y \text { são duas métricas } \\
\text { e Ling as duas línguas comparadas }
\end{gathered}
$$

Para evitar que diferenças entre as escalas dos eixos $\mathrm{x}$ e y influenciassem os resultados, os cálculos foram realizados com valores normalizados das métricas (z-score), que colocam os dois eixos na mesma escala (de desvios-padrão). Para que o leitor tenha uma noção da escala resultante, a figura 10 ilustra as distâncias euclidianas de 1,17 entre o inglês-L1 o inglês-L2 da primeira gravação, e de 0,47 entre o inglês-L1 e o inglês-L2 da quarta gravação no plano formado por $\Delta \mathrm{C}$ e \%V.

Figura 10: Distâncias euclidianas entre inglês-L1-L2(1) e inglês-L1-L2(4) no plano cartesiano das métricas $\Delta \mathrm{C}$ e $\% \mathrm{~V}$.

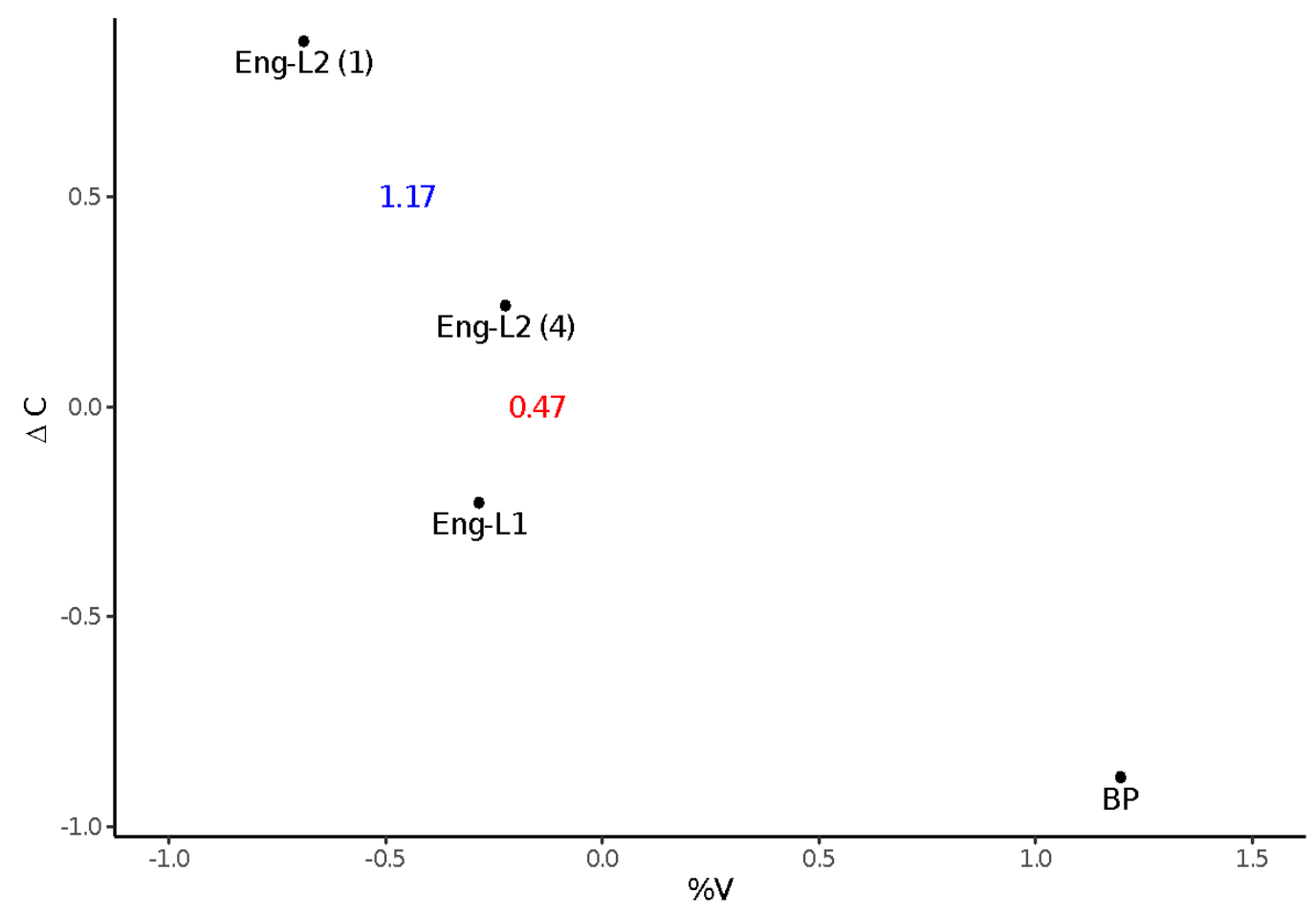

Fonte: Autores. 
A tabela 5 apresenta as distâncias euclidianas nos planos rítmicos analisados:

Tabela 5: Distâncias euclidianas entre inglês-L1 e interlínguas, e entre as L1s.

\begin{tabular}{ccc}
\hline \multirow{2}{*}{ Métrica } & Línguas & $\begin{array}{c}\text { Distância } \\
\text { Euclidiana }\end{array}$ \\
\hline \multirow{3}{*}{$\Delta \mathrm{C}-\% \mathrm{~V}$} & PB-L1 - inglês-L1 & 1,62 \\
& Inglês-L1 - L2(1) & 1,17 \\
& Inglês-L1 - L2(4) & 0,47 \\
\hline \multirow{3}{*}{ Varcos } & PB-L1 - inglês-L1 & 0,75 \\
& Inglês-L1 - L2(1) & 0,59 \\
& Inglês-L1 - L2(4) & 0,13 \\
\hline \multirow{3}{*}{ PVIs } & PB-L1 - inglês-L1 & 1,12 \\
& Inglês-L1 - L2(1) & 0,91 \\
& Inglês-L1 - L2(4) & 0,36 \\
\hline
\end{tabular}

Fonte: Autores.

Para todas as métricas, a maior distância está entre o PB e o inglês-L1, seguida da distância entre o inglês-L1 e o inglês-L2 da primeira gravação, e com o inglês-L2 da quarta gravação sempre mais próximo ao inglês-L1. De modo geral, a métrica que posicionou as línguas de maneira mais distante foi $\Delta \mathrm{C}-\% \mathrm{~V}$, e a métrica que deixou as duas línguas menos separadas foi a que utilizou Varcos.

\section{DISCUSSÃO}

Os resultados obtidos para as métricas $\Delta \mathrm{C}-\% \mathrm{~V}$, VarcoC-VarcoV, e rPVI-CnPVI-V confirmaram grande parte das hipóteses levantadas. As métricas posicionaram o PB, o inglês-L1, o inglês-L2 (1) e o inglês-L2 (4) como ritmicamente diferentes em seus planos bidimensionais; e, individualmente, apenas nPVI-V e VarcoV não promoveram diferenças significativas para todas as (inter)línguas. Também foram detectadas diferenças rítmicas entre o inglês-L2 dos falantes nas duas diferentes etapas do desenvolvimento, com valores muito mais aproximados entre inglês-L2 (4) e inglês-L1, conforme as distribuições nos planos rítmicos e as distâncias euclidianas, o que pode ser atribuído ao efeito da instrução. Consequentemente, as métricas rítmicas da primeira gravação dos 
aprendizes foram mais dissimilares ao inglês-L1, mas também não foram mais próximas ao PB, como esperado devido à influência da prosódia da L1 sobre a L2. As médias do inglês-L1 (1) registraram valores ainda mais dissimilares em relação ao PB, perfazendo um percurso de desenvolvimento diferente do esperado.

Esse percurso inesperado, com a interlíngua em estágio mais inicial apresentando valores mais extremos em direção ao ritmo acentual tanto no eixo das métricas vocálicas quanto das métricas consonantais destoa de estudos que argumentam em favor da existência de um percurso universal de desenvolvimento do ritmo, que deveria desenvolver-se do mais silábico ao mais acentual, independentemente da L1 (BUNTA; INGRAM, 2007; LLÉO; RAKOW; KEHOE, 2007; ORDIN; POLYANSKAIA, 2015). Também não é possível de forma objetiva falar em transferência de padrões prosódicos da L1 para a L2, porque os valores registrados para o inglês-L2 (1) apresentam valores diametralmente opostos ao PB. Esse percurso de desenvolvimento é consistente com a definição de interlíngua que se apresenta como sistema relativamente independente da L1 e da L2 (LI; POST, 2014), e com a não linearidade do processo de desenvolvimento linguístico como processo dinâmico (DE BOT; LOWIE; VERSPOOR, 2007; DE BOT, 2008).

No entanto, isso também não quer dizer que as produções de aprendizes brasileiros iniciantes serão sempre mais acentuais. Vale ressaltar que o parâmetro utilizado neste estudo para caracterizar o estágio de desenvolvimento dos aprendizes foi o semestre na graduação em Letras-Inglês, o que não necessariamente indica um nível de proficiência mais inicial. É possível que esses aprendizes tenham de fato atravessado um estágio em que a realização rítmica do inglês-L2 apresentou padrões duracionais com menor variabilidade vocálica e consonantal (i.e., com maior tendência ao ritmo silábico), pela influência dos padrões prosódicos da L1. Além disso, pelo fato de estarem cursando à época um curso superior em Letras, e no esforço de realizarem foneticamente o inglês-L2 de maneira marcadamente distinta em relação ao $\mathrm{PB}$, os aprendizes podem ter mobilizado um processo de dissimilação de categorias fonéticas, imprimindo valores duracionais exagerados para manter a distinção entre L1 e L2, de maneira semelhante ao que é previsto no Modelo de Aprendizagem de Fala para o nível segmental (FLEGE, 1995, FLEGE; BOHN, 2021). À medida que os aprendizes avançaram no desenvolvimento da L2, e após terem cursado as disciplinas de Fonologia Segmental e Fonologia Suprassegmental da Língua Inglesa, os padrões temporais da realização fonética da interlíngua podem ter sido reorganizados de maneira mais próxima à produção do inglês pelos falantes nativos.

Importa discutir também os resultados obtidos pelas métricas deste estudo e suas capacidades previsoras para padrões rítmicos similares e dissimilares entre (inter) 
línguas. Partindo-se do pressuposto de que os quatro corpora analisados aqui têm ritmos distintos, as quatro métricas cumpriram o papel de posicionar cada (inter)língua em um local diferente do espaço gradiente de classificação rítmica, colocando apenas inglês-L1 e inglês-L2 (4) em maior proximidade, o que era previsto dado o desenvolvimento da interlíngua na quarta gravação (como em Lin e Wang [2005]). Em geral, as métricas consonantais do eixo $y(\Delta \mathrm{C}$, VarcoC e rPVI-C) apresentaram maior variabilidade $\mathrm{e}$ dispersão em comparação às métricas do eixo $x(\% \mathrm{~V}$, VarcoV e nPVI-V), sendo que os três modelos de regressão para as métricas consonantais apresentaram efeitos para todas as (inter)línguas, e, entre as métricas vocálicas, apenas $\% \mathrm{~V}$ teve o mesmo resultado.

A maior dispersão e variabilidade dos dados no eixo $y$ pode estar associada a diferentes taxas de elocução, uma vez que duas das métricas consonantais empregadas não são normalizadas para a taxa de elocução, embora haja indícios na literatura de que esse fator não exerça tanta influência sobre o escopo duracional dos intervalos consonantais (LOW; GRABE; NOLAN, 2000). Além disso, não é possível afirmar que as métricas normalizadas sempre serão mais robustas em relação às métricas não normalizadas. Por exemplo, no estudo de Arvaniti (2012), \%V, $\Delta \mathrm{C}$ e rPVI-C foram as mais consistentes e apresentaram maior efeito de língua do que Varcos e nPVI-V. Outra possível explicação para a maior variabilidade temporal dos eixos $y$, sobretudo para os dados do inglês-L2 (1), é o fato de termos analisado o parágrafo inicial do texto lido, com maior probabilidade de os participantes terem produzido os enunciados sob tensão e, consequentemente, com maior monitoramento da fala. Apesar dessa diferença em relação a estudos prévios, é evidente a coerência interna entre os dados do estudo, com o inglês-L1 e o PB ocupando posições claramente distintas nos planos rítmicos, como previsto pelas propostas, os dados do inglês-L2 (1) registrando valores mais extremos em ambos os eixos, e o inglês-L2 (4) posicionando-se mais próximo ao inglês-L1, o que foi constatado tanto visualmente quanto pelo cálculo das distâncias euclidianas.

A variabilidade dos resultados também foi verificada em relação aos estudos de referência. No geral, o PB apresentou valores mais próximos de línguas consideradas mais silábicas em relação ao ritmo. No entanto, houve inconsistência em relação aos valores de nPVI-V, já que valores menores para essa métrica são esperados para línguas de ritmo mais silábico, refletindo menor variabilidade entre os intervalos vocálicos consecutivos. Já o inglês-L1 apresentou médias consistentes em relação aos estudos de referência, embora com valores mais elevados para o eixo dos intervalos consonantais. É importante destacar que a variabilidade de resultados entre o presente estudo e estudos de referência pode estar relacionada também às escolhas metodológicas empregadas na 
coleta de dados. Por exemplo, Ramus, Nespor e Mehler (1999) utilizaram-se apenas da leitura de frases; Grabe e Low (2002) coletaram os dados a partir da leitura de um texto; e Arvaniti (2012) utilizou-se de três modos de enunciação distintos em sua análise: leitura de frases, leitura de texto e fala espontânea.

O percurso de desenvolvimento do ritmo da L2 flagrado nesta análise preliminar, que tende aos padrões prosódicos do inglês-L1, com uma maior organização temporal pelos aprendizes registrada pelas métricas dos dados do inglês-L2 (4), sugere efeitos da instrução explícita de pronúncia, uma vez que os dados do inglês-L2 (4) foram coletados após os falantes terem cursado as disciplinas Fonologia Segmental da Língua Inglesa e Fonologia Suprassegmental da Língua Inglesa. Portanto, é possível que a instrução explícita da pronúncia na aula de língua não nativa, com benefícios para o desenvolvimento de aspectos segmentais da pronúncia já reportados na literatura (LIMA JR., 2010; ALVES; MAGRO, 2011; LIMA JR.; ALVES, 2019), também exerça um efeito positivo no desenvolvimento de aspectos prosódicos em L2.

\section{CONCLUSÃO}

Respondendo a primeira questão que orientou este estudo, "Como as métricas $\triangle C, \% V, r P V I-C, n P V I-V$, VarcoC, e VarcoV posicionam o inglês-L1 norte-americano, o inglês-L2 de brasileiros, e o PB-L1?", todas as métricas analisadas posicionaram o inglês-L1 norte-americano, o inglês-L2 de brasileiros, e o PB-L1 em posições distintas no plano rítmico bidimensional formado pelas métricas analisadas, confirmando a primeira hipótese, de que são sistemas ritmicamente diferentes. Para a segunda pergunta, "Qual é o efeito do ensino explícito de pronúncia no desenvolvimento do ritmo do inglês-L2 dos aprendizes?", há indícios de que o ensino explícito de pronúncia exerceu efeito positivo no processo de desenvolvimento do ritmo da L2, pois foi confirmada a hipótese de que os dados do inglês-L2 (1) seriam mais dissimilares em relação ao inglês-L1 em comparação aos dados do inglês-L2 (4). Já a direção do desenvolvimento partiu de uma direção diametralmente oposta à esperada, já que os valores do inglês-L2 (1) se distanciaram ainda mais daqueles do $\mathrm{PB}$, o que nos leva à terceira e última pergunta norteadora deste estudo - "Qual é a influência do ritmo do PB-L1 no desenvolvimento do inglês-L2 dos aprendizes?". Nossos dados não revelaram transferência direta de padrões rítmicos do PB, como inicialmente hipotetizado. No entanto, mais investigações são necessárias, pois, neste estudo, os aprendizes do primeiro semestre não necessariamente apresentavam um perfil de proficiência iniciante, podendo ter mobilizado um processo de dissimilação fonética com o objetivo de realizar L1 e L2 de maneira marcadamente distinta. 
Esse percurso de desenvolvimento atípico corrobora a ideia de interlíngua (e língua) enquanto sistema dinâmico e não linear, pois os dados do inglês-L2 (1) apresentaram uma desorganização temporal, com altos níveis de variabilidade e dispersão, mas tendendo aos padrões rítmicos do inglês-L1, o que fica mais evidente na constatação de maior proximidade dos dados do inglês-L2 (4) com o inglês-L1 em todas as métricas verificadas. A menor diferença entre inglês-L1 e inglês-L2 (4), após os aprendizes terem cursado as disciplinas de Fonologia Segmental da Língua Inglesa e Fonologia Suprassegmental Língua Inglesa, sugere também que o desenvolvimento da prosódia em aprendizes de L2 pode beneficiar-se do ensino explícito de pronúncia.

Uma das limitações deste estudo foi o número de métricas rítmicas empregadas, apenas seis, e o tipo, pois todas mensuram duração. As futuras etapas deste estudo incluem a incorporação de um maior número de métricas rítmicas, bem como de parâmetros acústicos associados a outros correlatos de proeminência, tais como frequência fundamental $\left(f_{0}\right)$, e aplicados a outros intervalos de referência, como sílabas fonéticas (VV), sentenças (S) e unidades sintático-prosódicas (chunks). Dessa forma, será possível refinar a descrição rítmica das línguas e interlínguas de maneira multidimensional, e investigar de maneira mais pormenorizada o processo de desenvolvimento da prosódia do inglês-L2 por aprendizes brasileiros, verificando os efeitos da L1 e do ensino explícito de pronúncia nesse percurso. Outra limitação deste estudo diz respeito à quantidade de sentenças analisadas, apenas sete. É possível que a análise de um número maior de sentenças no futuro resulte em mais estabilidade nos índices métricos (ARVANITI, 2012). Assim, as análises futuras deverão incluir também os corpora das gravações 2 e 3, para uma abordagem mais longitudinal, além de incluir os outros dois parágrafos do texto lido.

Os resultados obtidos neste estudo demonstram a utilidade das métricas rítmicas para a descrição do desenvolvimento do ritmo em L2. Acreditamos que nas futuras etapas desta pesquisa, a expansão do inventário de métricas rítmicas, dos intervalos de referência e dos correlatos de proeminência aplicados a este estudo permitirá uma caracterização ainda mais precisa do desenvolvimento do ritmo por aprendizes brasileiros de L2, a partir de uma perspectiva multidimensional.

\section{REFERÊNCIAS}

ABERCROMBIE, D. Elements of general phonetics. Chicago: Aldine, 1967.

ADAMS, C. English speech rhythm and the foreign learner. Haia: Mouton, 1979. 
ALVES, U. K.; MAGRO, V. Raising awareness of L2 phonology: explicit instruction and the acquisition of aspirated /p/ by Brazilian Portuguese speakers. Letras de Hoje, Porto Alegre, v. 46, n. 3, p. 71-80, 2011.

ARVANITI, A. The usefulness of metrics in the quantification of speech rhythm. Journal of Phonetics, v. 40, n. 3, p. 351-373, 2012. Disponível em: http://dx.doi.org/10.1016/j. wocn.2012.02.003. Acesso em: 10 fev. 2021.

BALTAZANI, M. Prosodic rhythm and the status of vowel reduction in Greek. Selected papers on theoretical and applied linguistics from the 17th international symposium on theoretical \& applied linguistics, vol. 1, p. 31-43, 2007. Disponível em: https:// www.enl.auth.gr/symposium/publication.html. Acesso em 16 maio 2021.

BARBOSA, P. A. Incursões em torno do ritmo da fala. Campinas: Pontes, 2006.

BARBOSA, P.A. Conhecendo melhor a prosódia: aspectos teóricos e metodológicos daquilo que molda nossa enunciação. Revista de Estudos da Linguagem, v. 20, n. 1, 2012.

BEST, C. T. A direct-realist view of cross-language speech perception. In: STRANGE. W. (Ed.). Speech Perception and Linguistic Experience: Issues in Cross-Language Research. Timonium: York Press, 1995. p. 171-204.

BEST, C. T.; TYLER, M. D. Nonnative and second-language speech perception: Commonalities and complementarities. In: BOHN, O. S.; MUNRO, M. J. (Orgs.). Language experience in second language speech learning: In honor of James Emil Flege. Philadelphia: John Benjamins Publishing Company, 2007. p. 13-34.

BOERSMA, P.; WEENINK, D. Praat: doing phonetics by computer. (Version 6.0). http://www.praat.org, 2020.

BUNTA, F.; INGRAM, D. The acquisition of speech rhythm by bilingual Spanish- and English speaking 4- and 5-year-old children. Journal of Speech, Language, and Hearing Research, v. 50, n. 4, p. 999-1014, 2007.

CELCE-MURCIA, M.; BRINTON, D. M.; GOODWIN, J. M. GRINER, B. Teaching Pronunciation: a course book and reference guide. Cambridge: Cambridge University Press, 2010.

CUMMING, R. E. Speech rhythm: the language-specific integration of pitch and duration. 2010. 268 f. Tese (Doutorado em Filosofia) - Downing College. Cambridge Universidade de Cambridge, Cambridge, 2010. Disponível em: https://www.repository. cam.ac.uk/handle/1810/228685. Acesso em: 27 mar. 2021. 
DAUER R. M. Phonetic and Phonological Components of Language Rhythm. In: Proceedings of the $\mathbf{1 1}^{\text {th }}$ International Congress of Phonetic Sciences, 11., 1987, Tallinn. Londres: International Phonetic Association, 1987. p. 447-450.

DAUER, R. M. Stress-timing and syllable-timing realyzed. Journal of Phonetics, v. 11, n. 1, p. 51-62, 1983. Disponível em: https://doi.org/10.1016/S0095-4470(19)30776-4. Acesso em: 30 jan. 2021.

DE BOT, K. Introduction: Second language development as a dynamic process. The Modern Language Journal, v. 92, n. 2, p. 166-178, 2008.

DE BOT, K.; LOWIE, W.; VERSPOOR, M. A Dynamic Systems Theory approach to second language acquisition. Bilingualism: Language and Cognition, v. 10, n. 1, p. 7-21, 2007.

DELLWO, V. Rhythm and Speech Rate: A Variation Coefficient for deltaC. In: KARNOWSKI, P.; SZIGETI, I. (Eds.). Language and language-processing. Frankfurt: Peter Lang, 2006. p. 231-241.

DELLWO, V. The role of speech rate in perceiving speech rhythm. In: Proceedings of Speech Prosody, 4., 2008, Campinas: International Speech Communication Association, 2008. p. 375-378.

DELLWO, V.; FOURCIN, A. J.; ABBERTON, E. R. Rhythmical classification of languages based on voice parameters. In: Proceedings of the $\mathbf{1 5}^{\text {th }}$ International Congress of Phonetic Sciences, 15., 2007, Barcelona. Londres: International Phonetic Association, 2007. p. 1129-1132.

DELLWO, V; WAGNER, P. Relationships between speech rate and rhythm. In: Proceedings of the International Congress of Phonetic Sciences. 2003.

DING, H.; XU, X. L2 English Rhythm in Read Speech by Chinese Students. In: Proceedings of Interspeech, 17., 2016, São Francisco. São Francisco: International Speech Communication Association, 2016. p. 2696-2700.

FLEGE, J. Second Language Speech Learning: Theory, Findings and Problems. In: STRANGE, W. (Ed.). Speech perception and linguistic experience: issues in crosslanguage research. Timonium, York Press, 1995. p. 233-277.

FLEGE, J.; BOHN, O. The Revised Speech Learning Model (SLM-r). In: WAYLAND, R. (Ed.). Second Language Speech Learning: Theoretical and Empirical Progress. Cambridge: Cambridge University Press, 2021. p. 03-83. 
FUCHS, R. Speech rhythm in varieties of English. 1. Ed. Singapore: Springer, 2016.

GRABE, E; LOW, E. Durational variability in speech and the rhythm class hypothesis. In: GUSSENHOVEN C.; WARNER, N. (Eds.), Papers in Laboratory Phonology, 2002. p. $515-546$.

GUT, U. Rhythm in L2 speech. Speech and Language Technology. n.14, v.15, p. 83-94, 2012.

JEON, H. S. Acoustic measure of speech rhythm: Korean learners of English. Dissertação (Mestrado em Ciências), University of Edinburgh, Edinburgh, 2006.

LADEFOGED, P. A Course in Phonetics. New York: Harcourt Brace Jovanovich, Inc., 1975 .

LADEFOGED, P.; JOHNSON, K. A course in phonetics. Cengage learning, 2014.

LI, A.; POST, B. L2 acquisition of prosodic properties of speech rhythm: evidence from L1 Mandarin and German Learners of English. Studies in Second Language Acquisition, v. 36, n. 2, p. 223-255, 2014. Disponível em: https://doi.org/10.1017/S0272263113000752. Acesso em: 12 abr. 2021.

LIMA JR., R. M. Uma investigação dos efeitos do ensino explícito da pronúncia na aula de inglês como língua estrangeira. RBLA - Revista Brasileira de Linguística Aplicada, Belo Horizonte, v. 10, n. 3, p. 747-771, 2010.

LIMA JR., R. M; ALVES, U. K. A dynamic perspective on L2 pronunciation development: bridging research and communicative teaching practice. Revista do GEL, v. 16, n. 2, p. 27-56, 2019.

LIN, H. L.; WANG, Q. Vowel Quantity and Consonant Variance: A Comparison between Chinese and English. In: Proceedings of Between Stress and Tone Conference, Leiden, 2005.

LISS, J. M.; WHITE, L.; MATTYS, S. L.; LANSFORD, K.; LOTTO, A. J.; SPITZER, S. M.; CAVINESS, J. N. (2009). Quantifying speech rhythm abnormalities in the dysarthrias.. Quantifying speech rhythm abnormalities in the dysarthrias. Journal of Speech, Language and Hearing Research, n.52, v.5, p. 1334-1352. 2009.

LLÉO, C.; RAKOW, M.; KEHOE, M. Acquiring Rhythmically Different Languages in a Bilingual Context. In: Proceedings of $\mathbf{1 6}^{\text {th }}$ International Congress of Phonetic Sciences, 16., 2007, Saarbrücken: Universität des Saarlandes, 2007. p. 1545-1548. 
LOUKINA, A.; KOCHANSKI, G.; SHIH, C.; KEANE, E.; WATSON, I. Rhythm measures and dimensions of durational variation in speech. The Journal of the Acoustical Society of America, v. 129, n. 5, p. 3258-3270, 2011.

LOW, E. L.; GRABE, E.; NOLAN, F. Quantitative characterizations of speech rhythm: Syllable-timing in Singapore English. Language and Speech, v. 43, n. 4, p. 377-401, 2000.

MOK, P. P. K.; LEE, S. I. Korean speech rhythm using rhythmic measures. Apresentação no 18th International Congress of Linguists (CIL18). Seoul, Korea, 2008.

MUNRO, M. J.; DERWING, T. M. Modeling perceptions of the accentedness and comprehensibility of 12 speech: the role of speaking rate. Studies in Second Language Acquisition, v. 23, n. 4, p. 451-468, 2001.

ORDIN, M.; POLYANSKAYA, L. Acquisition of speech rhythm in a second language by learners with rhythmically different native languages. The Journal of the Acoustical Society of America, v. 138, n. 2, p. 533-544, 2015.

RAMUS, F.; NESPOR, M.; MEHLER, J. Correlates of linguistic rhythm in the speech signal. Cognition, v. 73, n. 3, p. 265-292, 1999.

RATHCKE, T.; SMITH, R. Exploring timing in accents of British English. In: Proceedings of the $17^{\text {th }}$ International Congress of Phonetic Sciences, 17., 2011, Hong Kong. Londres: International Phonetic Association, 2011. p.1666-1669.

RUSSO, M.; BARRY, W. J. Isochrony reconsidered - objectifying relations between rhythm measures and speech tempo. In: Proceedings of Speech Prosody 2008, Campinas, Brazil, 2008.

SILVA JR., L.; BARBOSA, P. Metrics \& Acoustics Extractor version 1.0. Script for Praat. 2019a.

SILVA JR., L.; BARBOSA, P. Speech rhythm of English as L2: as investigation of prosodic variables on the production of Brazilian Portuguese speakers. Journal of Speech Sciences, v. 8, n. 2, p. 37-57, 2019b.

THOMSON, R. I.; DERWING, T. M. The Effectiveness of L2 Pronunciation Instruction: A narrative Review. Applied Linguistics, v. 36, n. 3, p. 326-344, 2015.

TSIARTSIONI, E. The acquisition of features of rhythm and stop voicing in Greek and English L2. 2003. Dissertação (Mestrado em Filosofia) - Center for Language and Communication Studies, Trinity College Dublin, 2003. 
WHITE, D.; MOK, P. L2 Speech Rhythm and Language Experience in New Immigrants. In: Proceedings of the $\mathbf{1 9}^{\text {th }}$ International Congress of Phonetic Sciences, 19. 2019, Melbourne. Londres: International Phonetic Association, 2019. p. 1-5.

WHITE, L.; MATTYS, S. L. Calibrating rhythm: First language and second language studies. Journal of Phonetics, v. 35, n. 4, p. 501-522, 2007.

WHITWORTH, N. Speech rhythm production in three German-English bilingual families. Leeds Working Papers in Linguistics and Phonetics, v. 9, n. 3, p. 175-205, 2002.

\section{ANEXOS}

\section{Anexo A: Texto em inglês.}

Is English your native language? If not, your foreign accent may show people that you come from another country. Why is it difficult to speak a foreign language without an accent? There are a couple of answers to this question. First, age is an important factor in learning to pronounce. We know that young children can learn a second language with perfect pronunciation. We also know that older learners usually have an accent, though some older individuals also have learned to speak without an accent.

\section{Anexo B: Texto em português.}

O inglês é a sua língua nativa? Caso não seja, o seu sotaque estrangeiro pode mostrar para as pessoas que você vem de outro país. Por que é difícil falar uma língua estrangeira sem sotaque? Existem algumas respostas para essa pergunta. Primeiro, idade é um fator importante na aprendizagem da pronúncia. Nós sabemos que crianças pequenas conseguem aprender uma segunda língua com pronúncia perfeita. Também sabemos que aprendizes mais velhos normalmente têm sotaque, apesar de alguns aprendizes mais velhos também conseguirem aprender a falar sem sotaque algum.

Recebido em: 09 jun. 2021.

Aceito em: 04 jul. 2021. 